\title{
Preconditioning of bone marrow mesenchymal stem cells with hydrogen sulfide improves their therapeutic potential
}

\author{
Qun Zhang ${ }^{1}$, Song Liu ${ }^{1}$, Tong Li $^{1}$, Lin Yuan ${ }^{1}$, Hansen Liu ${ }^{2}$, Xueer Wang ${ }^{1}$, \\ Fuwu Wang ${ }^{3}$, Shuanglian Wang ${ }^{1}$, Aijun $\mathrm{Hao}^{3}$, Dexiang Liu' ${ }^{2}$, Zhen Wang ${ }^{1,3}$ \\ ${ }^{1}$ Department of Physiology, Shandong University School of Medicine, Jinan, Shandong 250012, P.R. China \\ ${ }^{2}$ Department of Medical Psychology, Shandong University School of Medicine, Jinan, Shandong 250012, P.R. China \\ ${ }^{3}$ Key Laboratory of the Ministry of Education for Experimental Teratology, Shandong Provincial Key Laboratory of Mental \\ Disorders, Department of Histology and Embryology, Shandong University School of Medicine, Jinan, Shandong 250012, \\ P.R. China
}

Correspondence to: Dexiang Liu, email: Liudexiang@sdu.edu.cn

Zhen Wang, email: wangzhen@sdu.edu.cn

Keywords: hydrogen sulfide, bone marrow mesenchymal stem cells, transplants, brain-derived neurotrophic factor, vascular endothelial growth factor

Received: February 08, $2016 \quad$ Accepted: July 27, $2016 \quad$ Published: August 09, 2016

\section{ABSTRACT}

Bone marrow mesenchymal stem cells (BMSCs) transplantation has shown great promises for treating various brain diseases. However, poor viability of transplanted BMSCs in injured brain has limited the therapeutic efficiency. Hypoxia-ischemic injury is one of major mechanisms underlying the survival of transplanted BMSCs. We investigated the mechanism of preconditioning of BMSCs with hydrogen sulfide (H2S), which has been proposed as a novel therapeutic strategy for hypoxia-ischemic injury. In this study, we demonstrated that preconditioning of NaHS, a H2S donor, effectively suppressed hypoxia-ischemic-induced apoptosis whereby the rise in Bax/ $\mathrm{BCl}-2$ ratio. Further analyses revealed Akt and ERK1/2 pathways were involved in the protective effects of NaHS. In addition, NaHS preconditioning increased secretion of BDNF and VEGF in BMSCs. Consistent with in vitro data, transplantation of NaHS preconditioned BMSCs in vivo further enhanced the therapeutic effects of BMSCs on neuronal injury and neurological recovery, associated with increased vessel density and upregulation of BDNF and VEGF in the ischemic tissue. These findings suggest that $\mathrm{H} 2 \mathrm{~S}$ could enhance the therapeutic effects of BMSCs. The underlying mechanisms might be due to enhanced capacity of BMSCs and upregulation of protective cytokines in the hypoxia tissue.

\section{INTRODUCTION}

A growing number of experimental studies highlights the potential of stem cell transplantation as a novel therapeutic approach for ischemic stroke [1] Moreover, a variety of clinical trials have been performed and others are currently ongoing [2]. Bone marrow-derived mesenchymal stem cells (BMSCs) are widely used in cell therapy because of their ease of acquisition and expansion, immune tolerance, and differentiation capacity $[3,4]$. Transplantation of BMSCs in the acute stage of ischemic stroke often modulates the inflammatory milieu, reduces lesion size and inhibits apoptosis in the penumbra area by providing neuroprotective paracrine factors $[3,5,6]$. However, only a small fraction of grafted cells survived in the ischemic brain $28 \mathrm{~d}$ after grafting because of the interplay of poor blood supply, ischemia reperfusion, inflammation, and apoptosis. Donor variability is another challenge for BMSC therapy trials.

Hydrogen sulfide $\left(\mathrm{H}_{2} \mathrm{~S}\right)$ has been classified as a novel gasotransmitter signaling molecule in the central nervous system (CNS), involving in the regulation of ion channels, neurotransmitter functions, and other intracellular signaling molecules such as tyrosine kinases [7]. Interestingly, accumulating evidence has been garnered which suggests that exogenous $\mathrm{H}_{2} \mathrm{~S}$ can function as a powerful neuroprotective agent. Kimura et al. demonstrated that $\mathrm{H}_{2} \mathrm{~S}$ protected primary rat cortical neurons from oxidative stressinduced injury [8]. $\mathrm{H}_{2} \mathrm{~S}$ exerts a number of cytoprotective and anti-inflammatory, anti-oxidant, and anti-apoptotic 
effects in CNS [9-11]. Recently, our findings showed the neuroprotective potential of $\mathrm{H}_{2} \mathrm{~S}$ in animal models of cerebral hypoxia injury $[12,13]$. Importantly, we observed that $\mathrm{H}_{2} \mathrm{~S}$ was able to promote proliferation and neuronal differentiation of neural stem cells, and protect against hypoxia-induced decrease in hippocampal neurogenesis [14]. Although there is only limited information about anti-apoptotic effect of the endogenous $\mathrm{H}_{2} \mathrm{~S}$ in BMSCs, the potential therapeutic value of $\mathrm{H}_{2} \mathrm{~S}$ for BMSCs transplant has been increasingly recognized [15].

In this study, we tested the hypothesis that preconditioning with sodium hydrosulfide (NaHS), a $\mathrm{H}_{2} \mathrm{~S}$ donor, enhances the survival of BMSCs upon exposure to hypoxia-ischemic insult in vivo and in vitro. We also sought to elucidate the underlying mechanisms of $\mathrm{H}_{2} \mathrm{~S}$ preconditioning in BMSCs.

\section{RESULTS}

\section{$\mathrm{H}_{2} \mathrm{~S}$ preconditioning promotes proliferation of BMSCs under hypoxia-ischemic condition}

The effects of various concentrations of $\mathrm{NaHS}$ $(0.1,0.5,1,5,10$ and $50 \mu \mathrm{M})$ on viability of BMSCs were assessed. MTT results showed that NaHS preconditioned BMSCs ( $\left.{ }^{\mathrm{PC}} \mathrm{BMSCs}\right)$ had a significant reduction in death, compared with the non-preconditioned BMSCs (non-PCBMSCs) after $48 \mathrm{~h}(p<0.01)$ and $72 \mathrm{~h}(p<0.01)$ hypoxia-ischemic injury. Furthermore, $1 \mu \mathrm{M}$ NaHS preconditioning yielded the optimal effect on cell viability $(82.8 \pm 6.07 \%$ vs $64.2 \pm 7.77 \%$ at $48 \mathrm{~h}, p<0.01$; and $108.9 \pm 9.12 \%$ vs $44.0 \pm 5.24 \%$ at $72 \mathrm{~h}, p<0.01$, respectively) (Figure 1A). Given the effectiveness of NaHS preconditioning at these concentrations $(0.1,1$ and $5 \mu \mathrm{M}$ ), this protocol was used in the most of the subsequent in vitro experiments, unless otherwise stated. In addition, cell viability following treatment with $\mathrm{NaHS}$ alone at $0.1 \mu \mathrm{M}(99.9 \pm 8.64 \%), 1 \mu \mathrm{M}(98.3 \pm 9.79 \%)$ and $5 \mu \mathrm{M}$ $(104.6 \pm 11.38 \%)$ was not significantly different from the control group $(100 \pm 9.75 \%)$ at $72 \mathrm{~h}$. To further confirm this result, the number of colonies was counted by crystal violet staining (Figure 1B and 1C). The result indicated that the number of MSCs preconditioned with NaHS $(1 \mu \mathrm{M})$ increased faster than that of hypoxia-ischemic exposure cells.

We then took BrdU staining assay to quantify the proliferating BMSCs, The result showed that the ratio of BrdU positive cells against total BMSCs were significantly decreased under the $72 \mathrm{~h}$ hypoxia-ischemic condition $(p<0.001)$, while the effects were significantly attenuated by co-treated with NaHS $(1 \mu \mathrm{M})$ (Figure 1B and 1D, $p<0.01$ ).

\section{$\mathrm{H}_{2} \mathrm{~S}$ preconditioning suppresses apoptosis of BMSCs under hypoxia-ischemic condition}

The TUNEL assay revealed that TUNEL-positive BMCSc were significantly increased under the $72 \mathrm{~h}$ hypoxia-ischemic condition $(p<0.001)$, while the effect of hypoxia-ischemic on apoptosis of cells was significantly attenuated by co-treated with NaHS $(1 \mu \mathrm{M})$ (Figure 1B and $1 \mathrm{E}, p<0.01$ ).

Depolarization of the inner MMP is a sign of apoptosis [16]. Therefore, in order to ascertain whether NaHS preserves mitochondrial integrity through the maintenance of MMP, we performed JC-1 staining. As shown in Figure 3B, the red/green ratio of JC-1 was decreased in the BMSCs exposed to hypoxia-ischemic insult compared with the normal group, and this effect was reversed by NaHS $(1 \mu \mathrm{M})$, which is consistent with the TUNEL assay (Figure 1B and 1F).

\section{$\mathrm{H}_{2} \mathrm{~S}$ preconditioning decreased $\mathrm{Bax} / \mathrm{Bcl}-2$ ratio in BMSCs under hypoxia-ischemic condition}

Because changes in expression of pro-apoptotic Bax and anti-apoptotic Bcl-2 control the mitochondrial pathway of apoptosis, we examined the expression of Bax and $\mathrm{Bcl}-2$ at the proteins and mRNA levels. As shown in Figure 2A and 2B, hypoxia-ischemic exposure markedly increased $\mathrm{Bax}$, decreased $\mathrm{Bcl}-2$, thereby increased the ratio of Bax/Bcl-2 at both protein and mRNA levels at $72 \mathrm{~h}$ post-injury ( $p<0.001, p<0.001$, respectively). However, this signal increase was reduced by preconditioning with $1 \mu \mathrm{M}$ NaHS $(p<0.001, p<0.001$, respectively). In addition, NaHS $(1 \mu \mathrm{M})$ treatment alone did not significantly alter the $\mathrm{Bax} / \mathrm{Bcl}-2$ ratio.

\section{$\mathrm{H}_{2} \mathrm{~S}$ preconditioning did not affect caspase-3 activation in BMSCs under hypoxia-ischemic condition}

To further investigate the potential protective mechanism of NaHS, we performed Western blot to assess cleaved-caspase-3 protein levels after hypoxia-ischemic insult. As shown in Figure 2C, hypoxia-ischemic exposure significantly increased cleaved-caspase- 3 protein levels $(p<0.01)$ compared with the corresponding controls. However, preconditioning with NaHS did not affect this hypoxia-ischemic induced cleaved-caspase-3 increase $(p>0.05)$.

\section{ERK1/2 and Akt pathway mediates the protection of $\mathrm{H}_{2} \mathrm{~S}$ preconditioning in BMSCs under hypoxia-ischemic condition}

The roles of ERK1/2 and Akt pathways upon the neuroprotective effects of $\mathrm{H}_{2} \mathrm{~S}$ were assessed using Western blot analysis. As shown in Figure 3A, the levels of phosphorylation of ERK1/2 and Akt were decreased when exposed to hypoxia-ischemic insult. Preconditioning with $1 \mu \mathrm{M}$ NaHS for 60, 120 and $240 \mathrm{~min}$ were all effective in up-regulating ERK1/2 activation in the hypoxia-ischemic group (Figure 3A). To implicate ERK1/2 in NaHS-induced 
protection against injury, BMSCs were treated with the specific blocker PD98059 to inhibit this pathway. PD98059 $(5 \mu \mathrm{M})$ reversed the effect of NaHS on ERK1/2 activation in the hypoxia-ischemic group (Figure 3B). Moreover, analysis by MTT showed that PD98059 (5 $\mu \mathrm{M})$ attenuated the anti-apoptotic effect of NaHS preconditioning after $72 \mathrm{~h}$ hypoxia-ischemic exposure (Figure 3C). In parallel with its effect on phosphorylation of ERK1/2, NaHS preconditioning for 5, 15 and $30 \mathrm{~min}$ caused a significant increase in Akt phosphorylation (Figure 3A). Administration of the potent PI3K inhibitor, wortmannin $(1 \mu \mathrm{M})$, markedly reversed the effect of NaHS

A

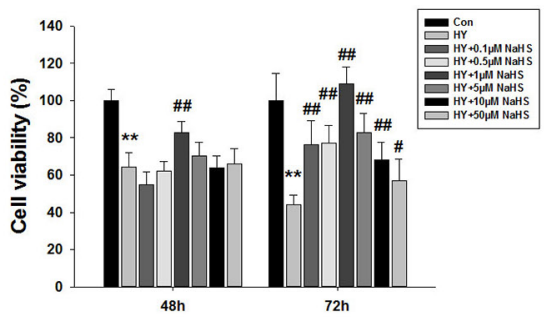

B Con
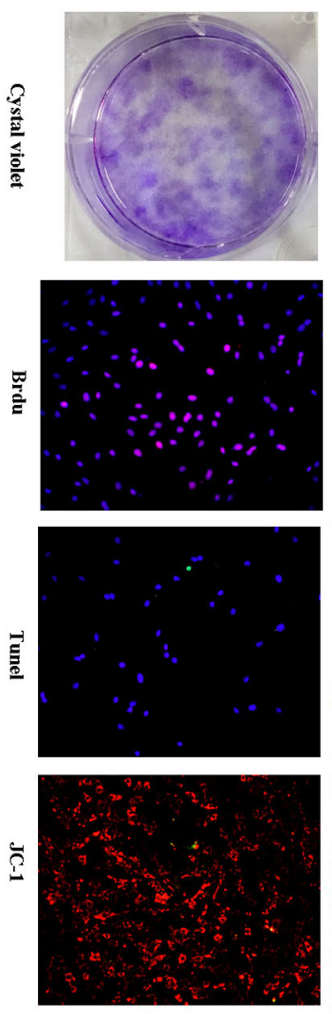

NaHS
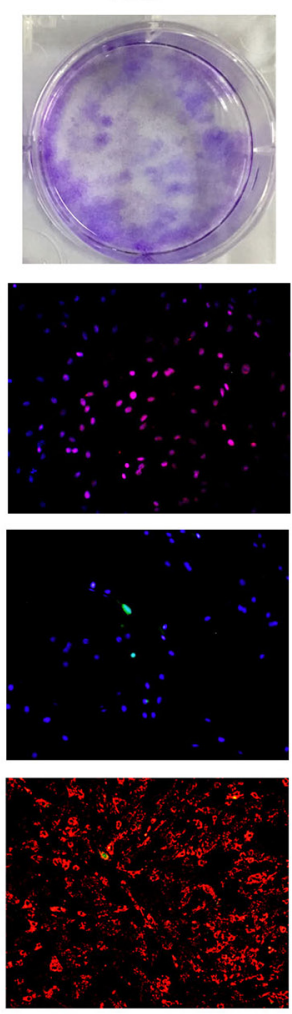

HY
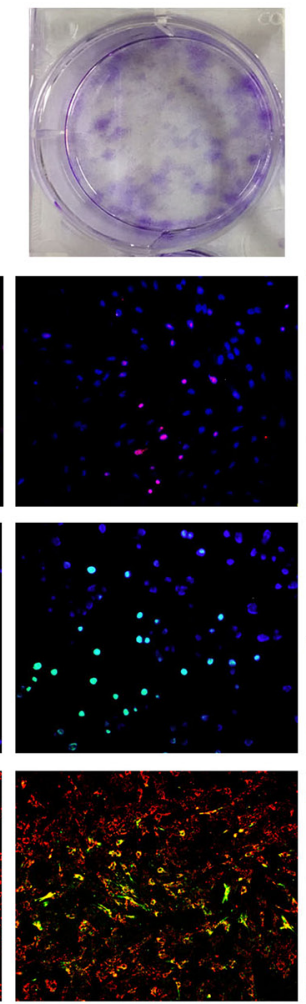

on Akt phosphorylation (Figure 3B), and blocked the antiapoptotic actions of NaHS after $72 \mathrm{~h}$ hypoxia-ischemic exposure (Figure 3C).

\section{$\mathrm{H}_{2} \mathrm{~S}$ preconditioning promotes $\mathrm{BDNF}$ and VEGF release from $\mathrm{BMSCs}$}

BMSCs have been shown to benefit neurological recovery after cerebral ischemia. The possible mechanisms are excreting trophic factors. Thus, we further investigated the effect of preconditioning BMSCs with NaHS $(1 \mu \mathrm{M})$ on neuroprotective factors such as BDNF and VEGF.
Hy+NaHS
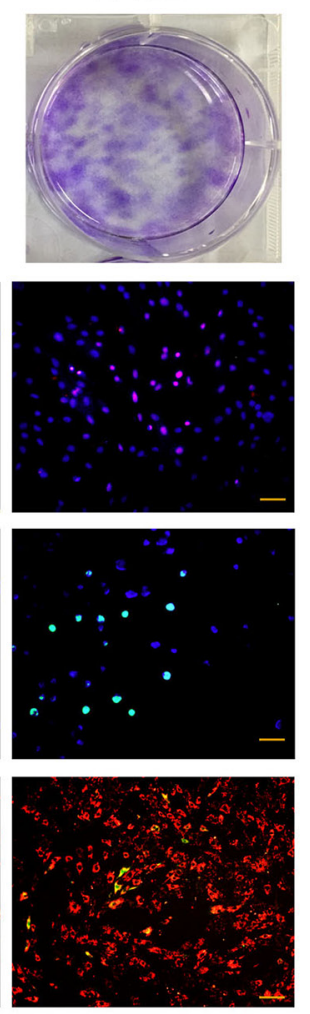

\section{C}

D
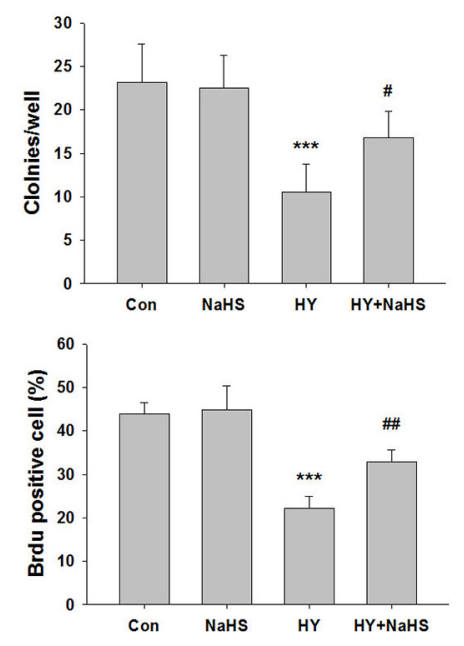

E

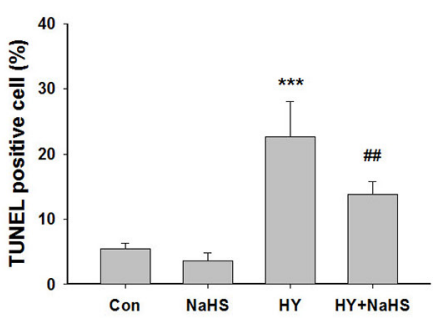

$\mathbf{F}$

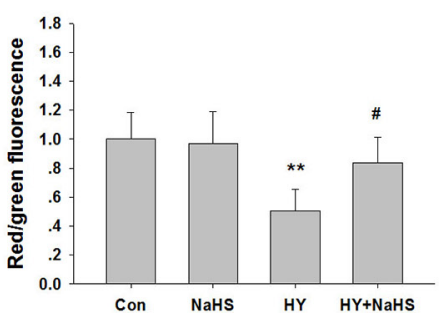

Figure 1: Effects of NaHS treatment on cell viability in bone marrow mesenchymal stem cells (BMSCs) in vitro. (A) BMSCs maintained in 1\% serum medium exposed to hypoxia (hypoxia-ischemic injury) were incubated in the absence or presence of indicated concentrations of NaHS $(0.1-50 \mu \mathrm{M})$ for $48 \mathrm{~h}$ and $72 \mathrm{~h}$ and cell viability was examined by MTT assay. Values of cell viability were expressed as a percentage relative to those obtained in controls. Values represent the mean \pm SD of $n=6$. (B) BMSCs exposed to hypoxia-ischemic were incubated in the absence or presence of indicated concentrations of NaHS $(1 \mu \mathrm{M})$ for $72 \mathrm{~h}$. The cells were then subjected to crystal violet assay, BrdU assay (red), tunnel staining, and JC-1 staining, counterstained with DAPI (blue). Scale bar $=50 \mu \mathrm{m}$. (C) The graphs indicate the number of positive colonies/well by crystal violet staining, $n=6$. (D) Quantification of BrdU positive BMSCs over the total DAPI-positive cells, $n=4$. (E) Quantification of Tunnel positive BMSCs over the total DAPI-positive cells. Values represent the mean $\pm \mathrm{SD}$ of $n=4$. (F) Quantitative analysis of the ratio of red/green fluorescence, $n=6$. Values represent the mean $\pm \mathrm{SD}$. $* * p<0.01$, $* * * p<0.001$ Hypoxia (Hy) VS Control (Con); \#p $<0.05$, \#\#p $<0.01$ Hy+ NaHS VS Hy. 
As shown in Figure 4A, NaHS treatment promoted RNA and proteins expression of BDNF and VEGF of BMSCs both in normal and hypoxia-ischemic conditions, compared with no NaHS treatment. Exposure to hypoxiaischemic insult slightly decreased VEGF mRNA in comparison to control group while the differences were not statistically significant (Figure 4A, $p>0.05$ ).

\section{$\mathrm{H}_{2} \mathrm{~S}$ preconditioning inhibits hypoxia-induced HIF-1a expression in BMSCs}

As shown in Figure 4B, hypoxia-ischemic exposure markedly increased HIF-1a at both protein and mRNA levels at $72 \mathrm{~h}$ post-injury $(p<0.01, p<0.01$,

A
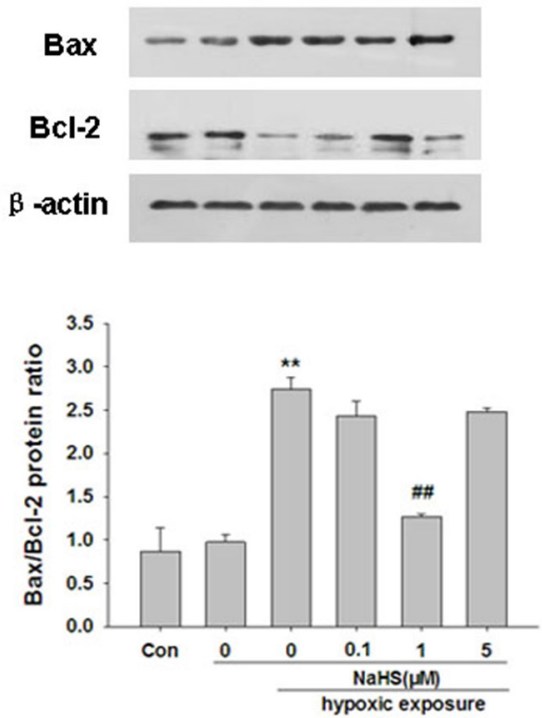

C

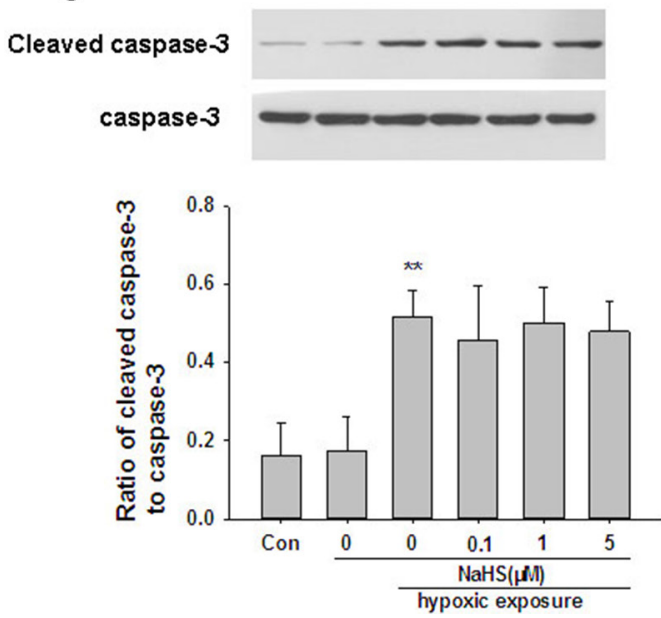

respectively). However, this signal increase was reduced by preconditioning with $1 \mu \mathrm{M}$ NaHS $(p<0.05, p<0.01$, respectively). In addition, $\mathrm{NaHS}(1 \mu \mathrm{M})$ treatment alone did not significantly alter the HIF-1a level.

\section{Administration of ${ }^{\mathrm{PC}} \mathrm{BMSCs}$ improves a greater neurological function in vivo}

To investigate the effects of ${ }^{\mathrm{PC}} \mathrm{BMSCs}$ in protecting neurons from hypoxia-ischemia injury in vivo, we established ischemic stroke models that were induced by $\mathrm{MCAO}$ in rats, and then transplanted ${ }^{\mathrm{PC}} \mathrm{BMSCs}$ into these rats intravenously. In the beginning, we evaluated neurological function using mNSS. The results showed
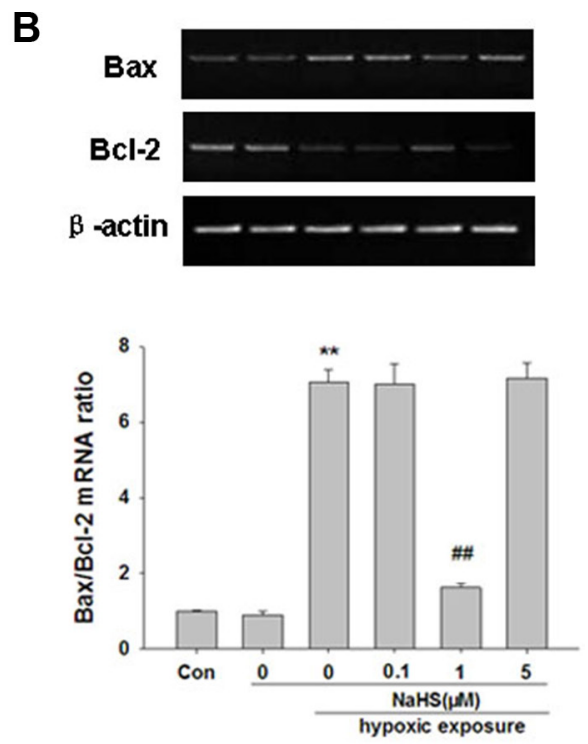

Figure 2: NaHS reverses hypoxia--ischemic induced changed of Bax and Bcl-2 and caspase-3 activation in BMSCs in vitro. (A-B) BMSCs exposed to hypoxia-ischemic were incubated in the absence or presence of NaHS $(1 \mu \mathrm{M})$ for $72 \mathrm{~h}$. The protein and mRNA levels of Bax and Bcl-2 were then analyzed by Western blot (A) and by semiquantitative RT-PCR (B). Levels of $\beta$-actin were used to evaluate protein loading. Results were expressed as Bax/Bcl-2 ratio. (C) BMSCs exposed to hypoxia-ischemic were incubated in the absence or presence of NaHS $(1 \mu \mathrm{M})$ for $72 \mathrm{~h}$. The cells extracts were subjected to Western blot analysis using an antibody against cleaved caspase-3, Levels of caspase-3 were used to evaluate protein loading. Quantification of the protein levels of cleaved caspase-3 and caspase-3 as determined by Image-Pro Plus 6.0. Values represent the mean \pm SD of $n=4 .{ }^{* *} p<0.01$ Hy VS Con; \#\#p<0.01 Hy+ NaHS VS Hy. 
A
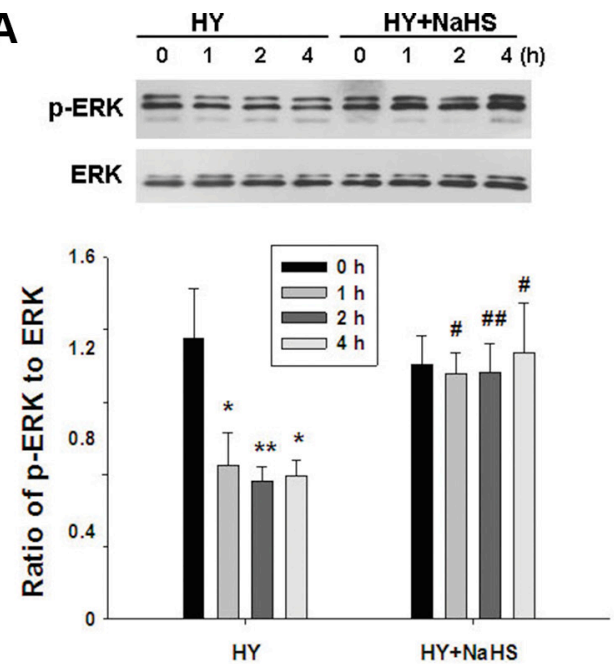

B
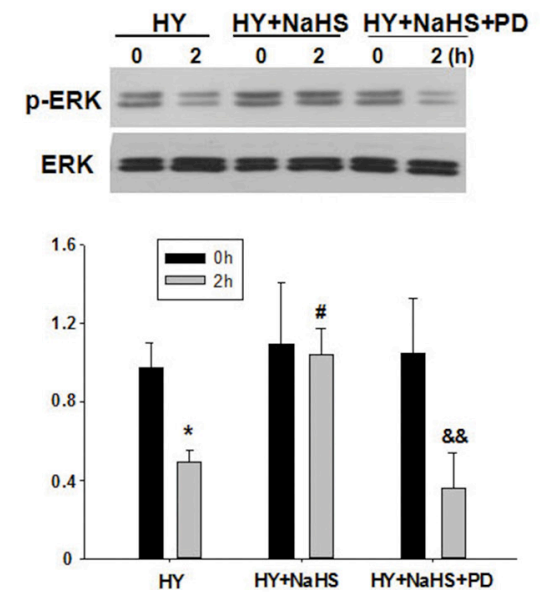

C

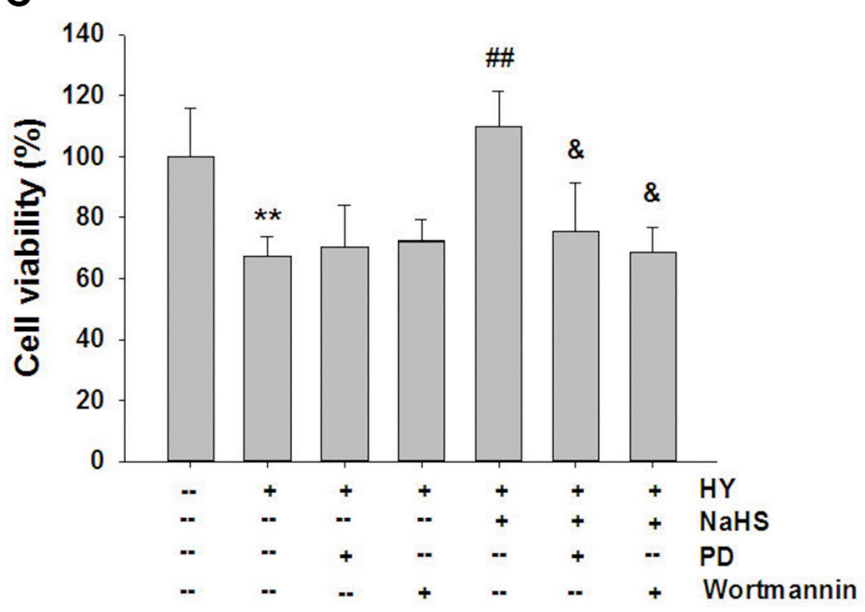

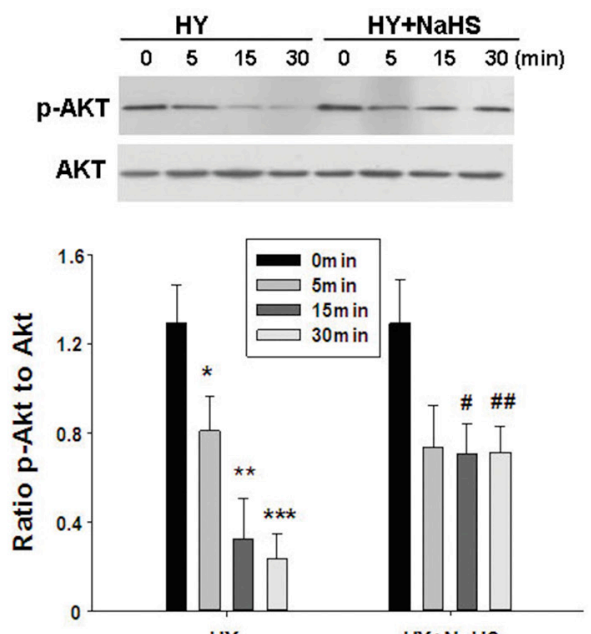

HY

$\mathrm{HY}+\mathrm{NaHS}$
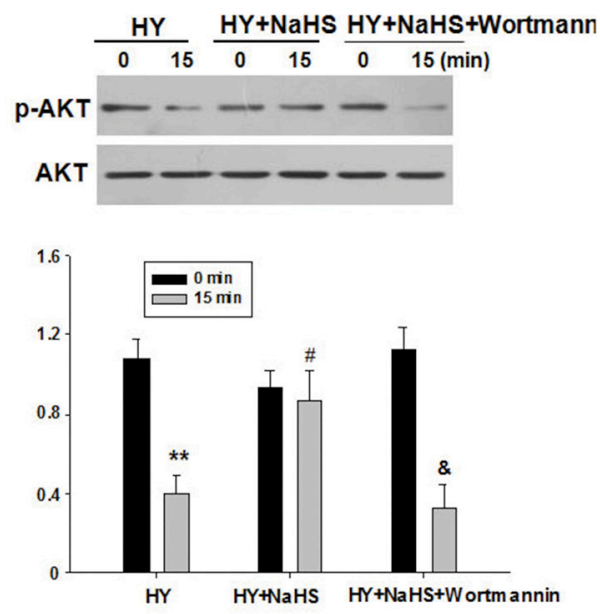

Figure 3: Effect of NaHS on ERK and Akt phosphorylation in BMSCs in vitro. (A) BMSCs exposed to hypoxia-ischemic were incubated in the absence or presence of NaHS $(1 \mu \mathrm{M})$ for indicated times and total protein was subjected to Western blot analysis. Bar graphs showing quantification of expression levels of phosphor-ERK/ERK or phosphor-Akt/Akt was determined by the Image-Pro Plus 6.0. $n=3$. (B) BMSCs exposed to hypoxia-ischemic were incubated in the absence or presence of NaHS (1 $\mu \mathrm{M})$, PD98059 (PD, $5 \mu \mathrm{M})$ or wortmannin $(1 \mu \mathrm{M})$ for indicated times and total protein was subjected to Western blot analysis. Bar graphs showing quantification of expression levels of phosphor-ERK/ERK or phosphor-Akt/Akt was determined by the Image-Pro Plus 6.0. $n=3$. (C) BMSCs were pretreated with PD98059 (PD, $5 \mu \mathrm{M}$ ) and wortmannin $(1 \mu \mathrm{M})$ for $30 \mathrm{~min}$, and then exposed to hypoxia-ischemic in the absence or presence of NaHS $(1 \mu \mathrm{M})$ for $72 \mathrm{~h}$. And cell viability was examined by MTT assay. Values of cell viability were expressed as a percentage relative to those obtained in controls, $n=6$. Values represent the mean \pm SD. ${ }^{*} p<0.05$, ${ }^{* *} p<0.01,{ }^{* * *} p<0.001$ Hy VS Con; \#p $<0.05$, \#\#p $<0.01$ $\mathrm{Hy}+\mathrm{NaHS}$ VS Hy; $\& p<0.05, \& \& p<0.01 \mathrm{HY}+\mathrm{PD} / \mathrm{HY}+$ wortmannin VS HY. 
there was no difference in mNSS among the no BMSCs group of rats (MACO group), ${ }^{\text {non-PC}} \mathrm{BMSCs}$ group and ${ }^{\mathrm{PC}} \mathrm{BMSC}$ groups at day $1[\mathrm{~F}(2,17)=0.166, p>0.05]$ and day $3[\mathrm{~F}(2,17)=1.099, p>0.05]$ after the transplantation. However, neurological deficits were improved in all groups at day 14 after transplantation $[\mathrm{F}(2,17)=20.043$,

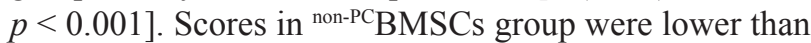
those in the sham control $(p<0.05)$. When compared with the ${ }^{\text {non-PC}} \mathrm{BMSC}$ group, transplantation with ${ }^{\mathrm{PC}} \mathrm{BMSCs}$ further reduced the scores $(p<0.05)$ (Figure 5A).
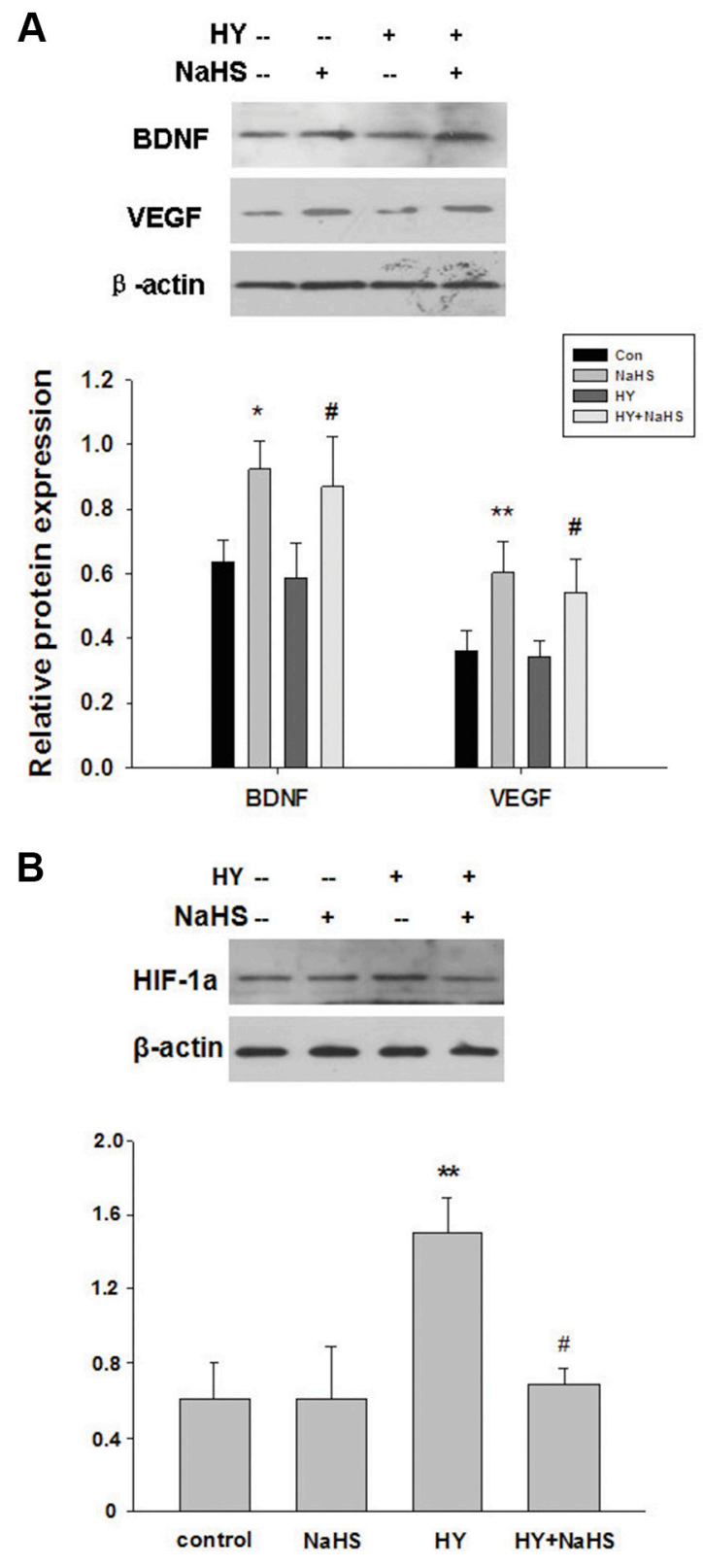

\section{Administration of ${ }^{\mathrm{PC}} \mathrm{BMSCs}$ reduces infarct volume following ischemic insults in vivo}

The pale stained area was determined to indicate the infarct area (Figure 5B and 5C). The infarct volume in the MACO group $(26.1 \% \pm 1.72 \%)$ was significantly larger than that in the non-PCBMSCs group $(19.1 \% \pm 2.76 \%$, $p<0.05)$ at day 14 after transplantation. When compared with the ${ }^{\text {non-PC}} \mathrm{BMSC}$ group, transplantation with ${ }^{\mathrm{PC}} \mathrm{BMSCs}$ $(12.2 \% \pm 2.08 \%, p<0.05)$ further reduced the infarct volume.
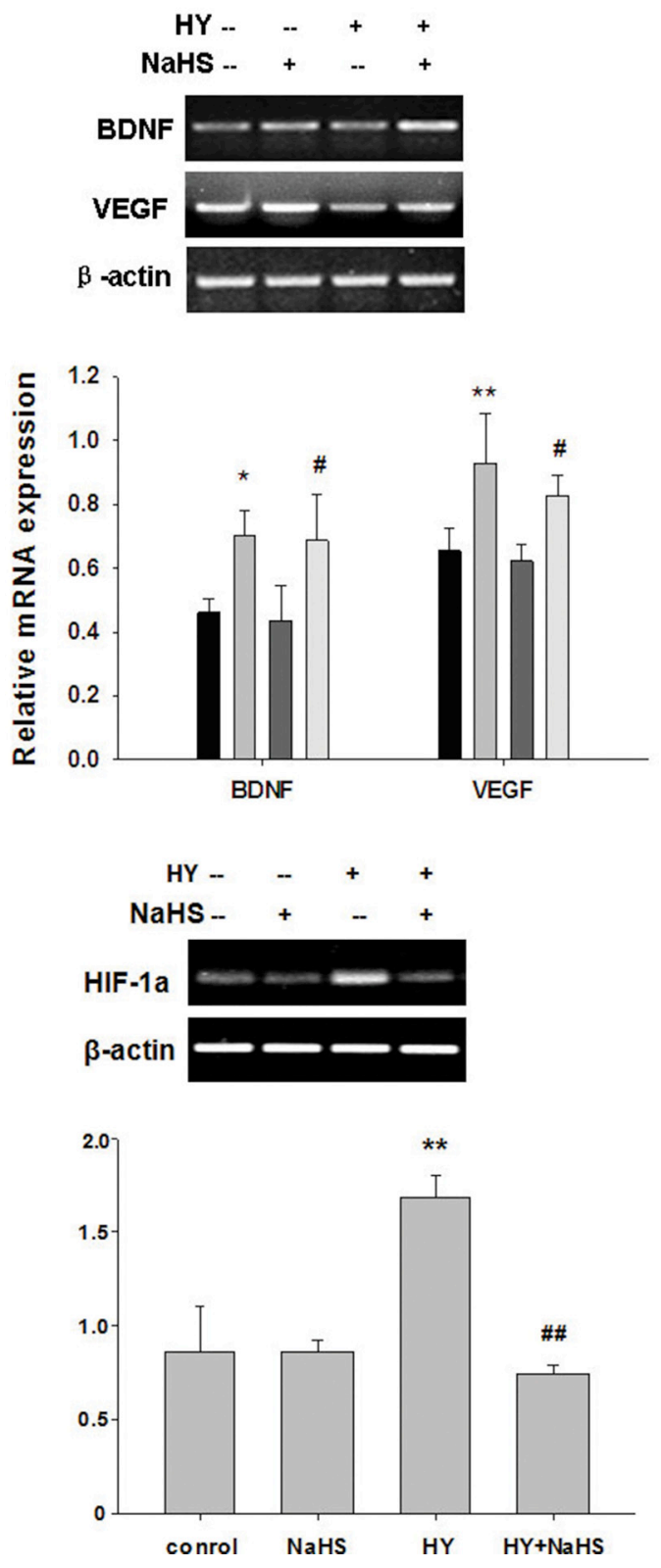

Figure 4: NaHS stimulated the release of BDNF and VEGF, and HIF-1a expression in BMSCs in vitro. (A) BMSCs exposed to hypoxia-ischemic were incubated in the absence or presence of NaHS $(1 \mu \mathrm{M})$ for $72 \mathrm{~h}$. The mRNA and protein levels of BDNF, VEGF, and $\beta$-actin were then analyzed by western blot and semiquantitative RT-PCR. (B) BMSCs exposed to hypoxia-ischemic were incubated in the absence or presence of NaHS $(1 \mu \mathrm{M})$ for $72 \mathrm{~h}$. The mRNA and protein levels of HIF-1a and $\beta$-actin were then analyzed by western blot and semiquantitative RT-PCR, Each value was normalized to $\beta$-actin. Data was expressed as the mean $\pm \operatorname{SD}$ of $n=4$. ${ }^{*} p<0.05$, $*^{*} p<0.01$ NaHS VS Con; \#p $<0.05, \# \# p<0.01 \mathrm{HY}+$ NaHS VS HY. 


\section{${ }^{\mathrm{PC}} \mathrm{BMSCs}$ transplantation reduces neuronal injury in vivo}

Next we examined the cell morphology by HE staining. In the MACO group, cells were arranged sparsely and the cell outline was fuzzy in the infarct zone. Moreover, obvious edema was found in the infarct zone, and more necrotic cells were found in MACO group, while non-PC BMSCs and ${ }^{\mathrm{PC}} \mathrm{BMSC}$ transplantation alleviated edema and these morphological damages (Figure 5D). Importantly, the amelioration of cellular morphology was more significant in ${ }^{\mathrm{PC}} \mathrm{BMSC}$ group than that in ${ }^{\text {non-PC}} \mathrm{BMSC}$ group. As shown in Figure 5D, the cell contour was distinguishable and nucleoli in the center of cells were observed clearly in ${ }^{\mathrm{PC}} \mathrm{BMSCs}$ group, and only a few neurons were shown to have nuclear pyknosis, hyperchromasia and extremely loose organization.

As shown in Figure 5D, MAP-2 immunolabeling was markedly diminished in the infarct zone, and there was an abrupt transition between the infarct and adjacent normal tissue with occasional MAP-2 positive cells in the transition zone in all groups. MAP-2 positive cells in the non-PC BMSCs and ${ }^{\mathrm{PC}} \mathrm{BMSCs}$ transplantation group were more than those in the MCAO group. Moreover, MAP-2 positive cells in the ${ }^{\mathrm{PC}} \mathrm{BMSC}$ group were significantly higher than those in the ${ }^{\text {non-PC}} \mathrm{BMSC}$ groups and (Figure 5D).

\section{Effect of ${ }^{\mathrm{PC}} \mathrm{BMSCs}$ on expression of CD31 in cerebral ischemia tissue after cerebral infarction}

CD31 is mainly distributed in vascular endothelial cells and it is usually used to evaluate the vessel density in the tissue. As shown in Figure 5D and 5E, compared with the MACO group, the number of CD31positive cells was increased in the non-PCBMSCs group and ${ }^{\mathrm{PC}} \mathrm{BMSCs}(p<0.01, p<0.05$, respectively) at day 14 after transplantation. The number of CD31-positive cells in the ${ }^{\mathrm{PC}} \mathrm{BMSC}$ group was significantly higher than that of the non-PCBMSCs $(p<0.05$, respectively) (Figure 5E).

\section{${ }^{\mathrm{PC} B M S C s}$ induces anti-apoptotic effect on neuronal cells in vivo}

Ischemia induced significant TUNEL-positive cells in the ischemic penumbra at day 14 after MCAO (Figure 6A). Quantitative analysis demonstrated that the number of TUNEL-positive cells in the non-PCBMSCs and ${ }^{\mathrm{PC} B M S C s}$ group was lower than that in the MACO group $(20.2 \% \pm 2.67$ vs $33.2 \% \pm 5.39 \%, p<0.001 ; 10.3 \pm 2.90$ vs $33.2 \% \pm 5.39 \%, p<0.001$, respectively). Of note, the number of TUNEL-positive cells in the ${ }^{\mathrm{PC} B M S C}$ group was significantly lower than that of the non-PC BMSCs groups $(10.3 \pm 2.90$ vs $20.2 \pm 2.67 \%, p<0.05)$ (Figure $6 \mathrm{~A}$ ).

\section{${ }^{\mathrm{PC}} \mathrm{BMSCs}$ decreases $\mathrm{Bax} / \mathrm{Bcl}-2$ ratio in vivo}

The results demonstrated that compared with the MACO group, the ratio of $\mathrm{Bax} / \mathrm{Bcl}-2$ protein was decreased in the ${ }^{\text {non-PC}} \mathrm{BMSC}$ group $(p<0.01)$. The ratio of $\mathrm{Bax} / \mathrm{Bcl}-2$ protein in the ${ }^{\mathrm{PC}} \mathrm{BMSC}$ group was significantly lower than that of ${ }^{\text {non-PC}} \mathrm{BMSC}$ groups $(p<0.05)$ (Figure $6 \mathrm{~B})$ at day 3 after transplantation. And there was no significantly difference between groups at day 14 after transplantation $(p>0.05)$ (Figure 6B). Similarly, the ratio of Bax/Bcl-2 mRNA was lower in the ${ }^{\text {non-PC}} \mathrm{BMSCs}$ group when compared with that of the MACO group at day 3 and 14 after transplantation $(p<0.001, p<0.001$, respectively). The ratio of $\mathrm{Bax} / \mathrm{Bcl}-2 \mathrm{mRNA}$ in the ${ }^{\mathrm{PC} B M S C}$ group was significantly lower than that of the ${ }^{\text {non-PC}} \mathrm{BMSCs}(p<0.01, p<0.05$, respectively) (Figure 6B).

\section{${ }^{\mathrm{PC}} \mathrm{BMSCs}$ improves BDNF and VEGF expression in vivo}

The levels of BDNF protein in the ${ }^{\text {non-PC}} \mathrm{BMSCs}$ group were significantly increased at day 3 and 14 after transplantation when compared with the MACO group ( $p<0.05, p<0.01$, respectively) (Figure 6C). Moreover, transplanted with NaHS preconditioned BMCSs further upregulated expression of BDNF protein at day 3 after transplantation $(p<0.01)$ (Figure $6 \mathrm{C}$ ). In addition, the levels of VEGF protein in the ${ }^{\text {non-PC}} \mathrm{BMSCs}$ group were significantly increased at day 14 after transplantation when compared with the MACO group $(p<0.01)$. Transplanted with NaHS preconditioned BMCSs further upregulated expression of VEGF protein at day 3 after transplantation $(p<0.01)$, when compared with the non-PC$B M S C$ group (Figure 6C).

As shown in (Figure 6C), non-PCBMSCs treatment significantly increased mRNA levels of BDNF at day 3 and 14 after transplantation ( $p<0.01, p<0.01$, respectively) and VEGF ( $p<0.001, p<0.001$, respectively), as compared to the MACO group. ${ }^{\mathrm{PC}} \mathrm{BMSC}$ groups treatment caused a further increase in the mRNA levels of BDNF at day 3 and 14 after transplantation $(p<0.01, p<0.05$, respectively) and VEGF ( $p<0.01, p<0.01$, respectively), when compared to the ${ }^{\text {non-PC}} \mathrm{BMSCs}$ group.

\section{DISCUSSION}

We have shown in this study that $\mathrm{H}_{2} \mathrm{~S}$ preconditioned BMCSs not only have a better survival rate than controls, but also express higher levels of BDNF and VEGF, resulting in stronger therapeutic effects in ischemic stroke. The major findings are: (a) $\mathrm{H}_{2} \mathrm{~S}$ protected BMCSs from hypoxia-ischemic injury via down-regulation of Bax/ Bcl-2 ratio in vitro and in vivo, (b) $\mathrm{H}_{2} \mathrm{~S}$ preconditioning increased the $\mathrm{BMCSs}$ to release $\mathrm{BDNF}$ and $\mathrm{VEGF}$ in vitro and in vivo, (c) $\mathrm{H}_{2} \mathrm{~S}$ increased the proliferation capacity of the BMCSs, via Akt and ERK1/2 pathways in vitro, 
(d) transplantation of the $\mathrm{H}_{2} \mathrm{~S}$ preconditioned BMCSs attenuated infarct size and improved neurological recovery in MACO rats.

The mechanisms responsible for the cytoprotective benefits of $\mathrm{H}_{2} \mathrm{~S}$ are not yet fully elucidated, but a number of suggestions have been provided. There are data which indicate that $\mathrm{H}_{2} \mathrm{~S}$ exerts its cytoprotective benefits against excitotoxic insult as demonstrated both in vitro $[17,18]$ or in vivo in neurons $[19,20]$, and $\mathrm{H}_{2} \mathrm{~S}$ also reduces cytotoxicity in astrocytes and microglia [21]. $\mathrm{H}_{2} \mathrm{~S}$ exerts its anti-apoptotic effects through various mechanisms, including inhibition of cytochrome $c$ release from mitochondria, normalized Bax /Bcl-2 levels, suppression of caspase-9/3 activation and poly(ADPribose) polymerase cleavage [7]. In this study, $\mathrm{H}_{2} \mathrm{~S}$ preconditioning reduced apoptosis in the BMSCs and resulted in down-regulation of $\mathrm{Bax} / \mathrm{Bcl}-2$ ratio after hypoxia-ischemic insult.

Akt and ERK pathways are involved in numerous crucial cell functions, such as proliferation, differentiation, motility, survival, and intracellular trafficking [22, 23]. And previous studies have shown that $\mathrm{H}_{2} \mathrm{~S}$ possesses neuroprotective effects in various models, some of which were dependent on the activity of the ERK and PI3K/Akt
A

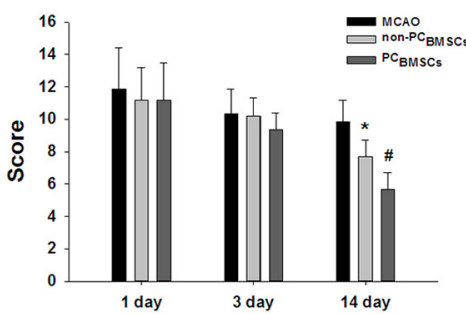

B

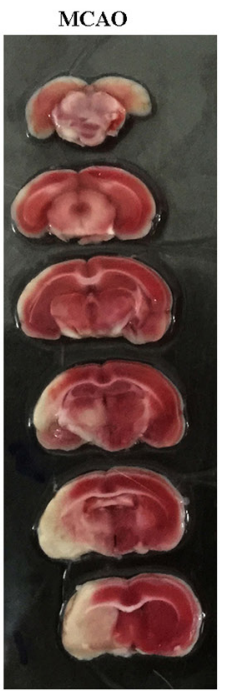

${ }^{\text {non-pc BMSCs }}$

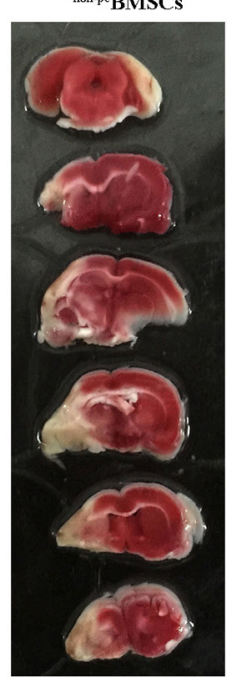

${ }^{\mathrm{pc}}$ BMSCs

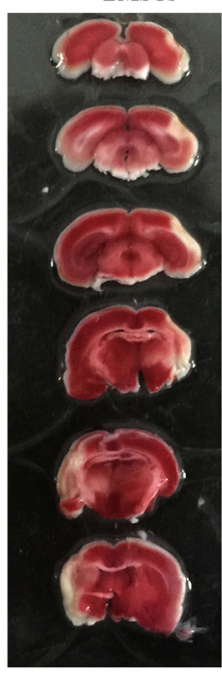

C

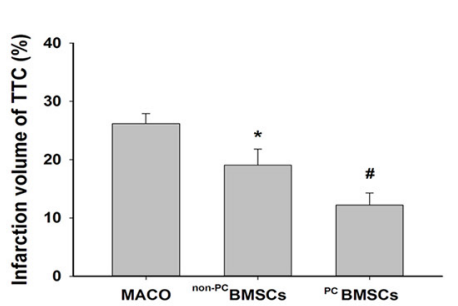

D

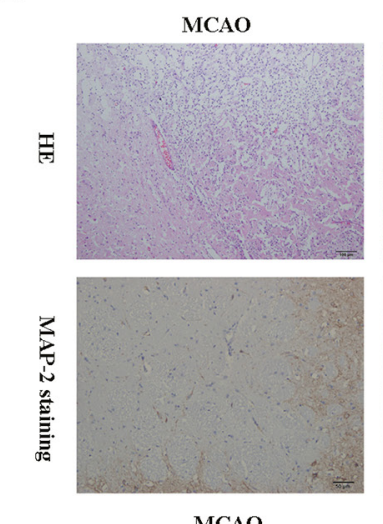

E

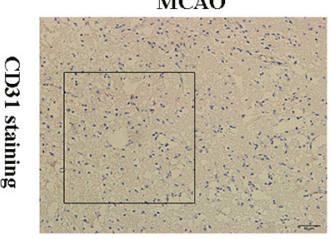

氙

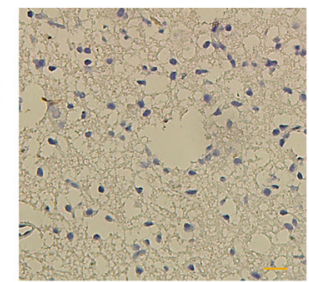

$\mathbf{F}$

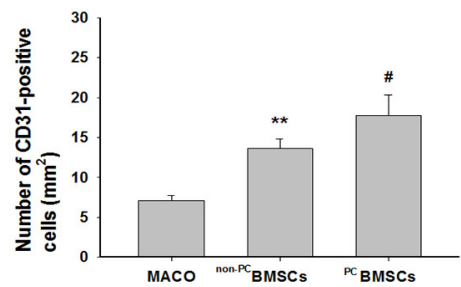

${ }^{\text {non-p }}$ BMSCs

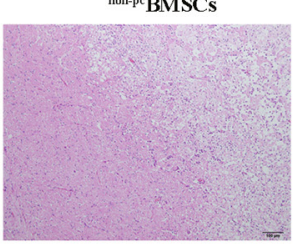

${ }^{\mathrm{pc} B M S C s}$
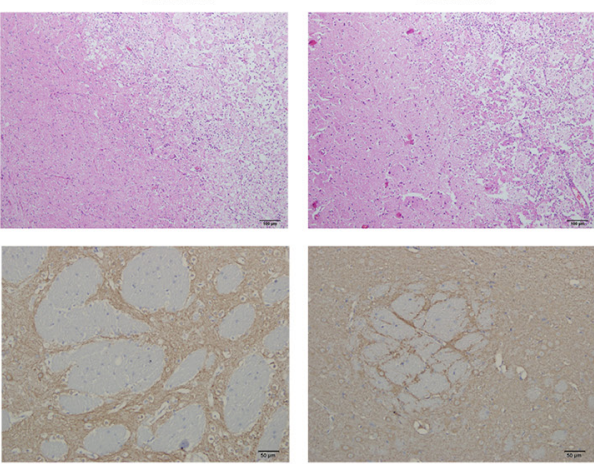

non $\mathrm{pc}$ BMSCs
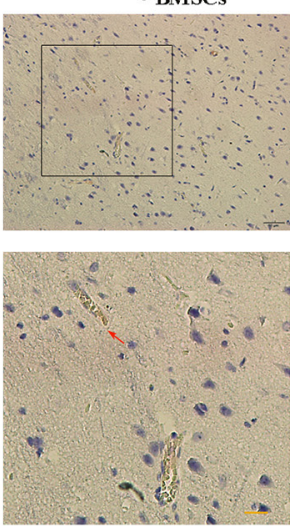

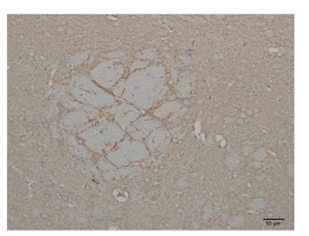

${ }^{\mathrm{pc} B M S C S}$
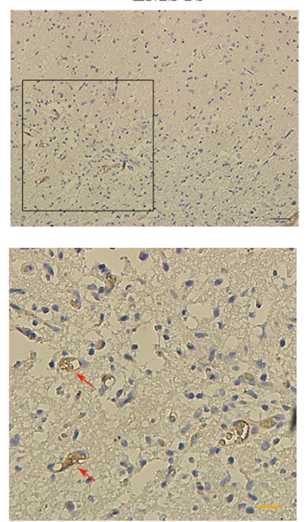

Figure 5: Administration of NaHS preconditioned-BMSCs (PCBMSCs) improved neurological function, decreased infarct volume, promoted neuronal density and MAP-2-positive cells in the infarct area. (A) The scores of mNSS were measured at day 1, 3 and 14 after BMSCs transplantation in MACO group, ${ }^{\text {non-PC} B M S C s}$ group and ${ }^{\mathrm{PC}} \mathrm{BMSCs}$ group. $n=6$. (B) Brain sections stained with TTC to visualize the ischemic lesions at day 14 after BMSCs transplantation in MACO group, ${ }^{\text {non-PC}} \mathrm{BMSCs}$ group and ${ }^{\mathrm{PC} B M S C}$ group. (C) Quantitative analysis of the Infarct Volume. $n=3$. (D) Representative photomicrographs $(\times 10)$ of the infarct area by HE staining. Scale bar $=100 \mu \mathrm{m} . n=4$. And Representative photomicrographs $(\times 20)$ of MAP-2 immunohistochemistry in the infarct area. Scale bar $=50 \mu \mathrm{m} . n=4$. (E) Representative photomicrographs of CD31 immunohistochemistry in the infarct area. Scale bar $=100 \mu \mathrm{m}$. (F) Quantitative analysis of CD31 positive cells. $n=4$. Values represent the mean $\pm \mathrm{SD}, * p<0.05,{ }^{*} p<0.05$ non-PCBMSCs VS MACO; $\# p<0.05{ }^{\mathrm{PC}} \mathrm{BMSCs}$ VS ${ }^{\text {non-PC}} \mathrm{BMSCs}$. 
signaling pathway. For example, $\mathrm{H}_{2} \mathrm{~S}$ therapy significantly suppressed caspase- 3 activation and decreased myocardial injury via activating the ERK signaling pathway [24]. Furthermore, by activating the PI3K/Akt signaling pathway, $\mathrm{H}_{2} \mathrm{~S}$ can increase $\mathrm{Bcl}-2$ protein levels, inhibit activation of the cytochrome c-caspase-3/9 apoptosis pathway, and promote the survival of cells [25]. In line with these findings, our data indicate that $\mathrm{H}_{2} \mathrm{~S}$ administration significantly enhanced Akt and ERK phosphorylation, and Akt or ERK inhibitor attenuated NaHS's promotion effects of cell survival, indicating that NaHS exerts its protective property in BMCSs after hypoxia-ischemic insult, at least in part, through the activation of Akt and ERK pathway.

Previous studies showed that intravenous administration of BMSCs after global cerebral ischemia decreased neural damage, suggesting that BMSCs increase neuron survival by intravenous infusion [6, 26, 27]. In this study, we found that BMSCs attenuated infarct size and improved the neurological deficits from day 14 after ischemic stroke and transplantation onward, indicating that neuroprotective effect is one of the main mechanisms of stem cell action in the present study. The paracrine factors produced by BMCSs such as VEGF [28], BDNF [29], and NGF [30] have a neuroprotective potential in animal ischemic stroke models. In vitro or in vivo, our results showed that BMSCs preconditioned by NaHS could enhance secretion of BDNF and VEGF, uniformly. In fact, previous studies have shown that $\mathrm{H}_{2} \mathrm{~S}$ treatment induces VEGF and angiogenic factor after ischemic stroke and improves neurological outcomes [31]. In addition, $\mathrm{H}_{2} \mathrm{~S}$ upregulates the level of BDNF protein and blockage of BDNF-TrkB pathway reverses the protection of $\mathrm{H}_{2} \mathrm{~S}$ against cytotoxicity, oxidative stress, and apoptosis in neurons [32, 33]. Importantly, to determine whether
A
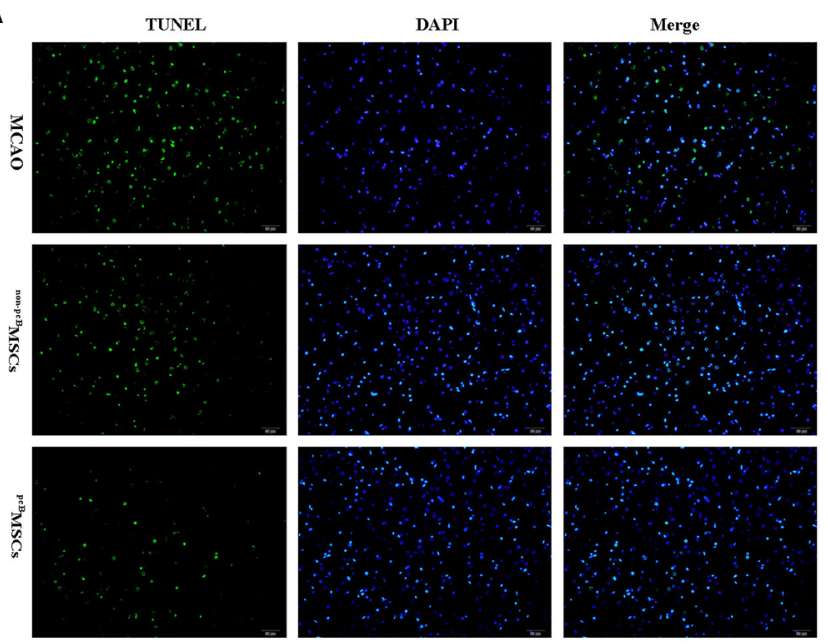

B
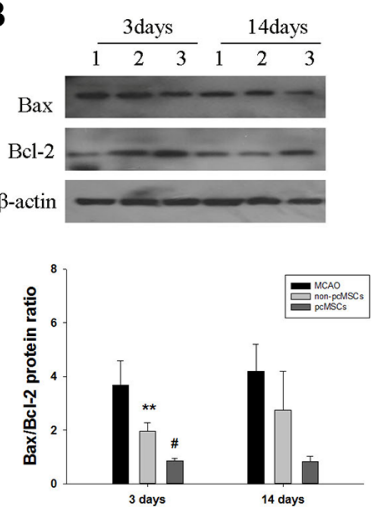
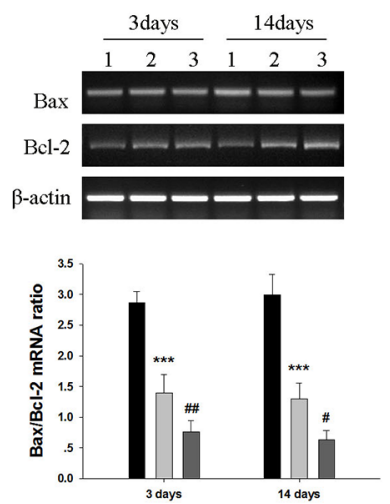

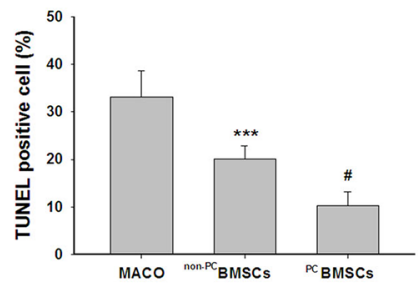

C
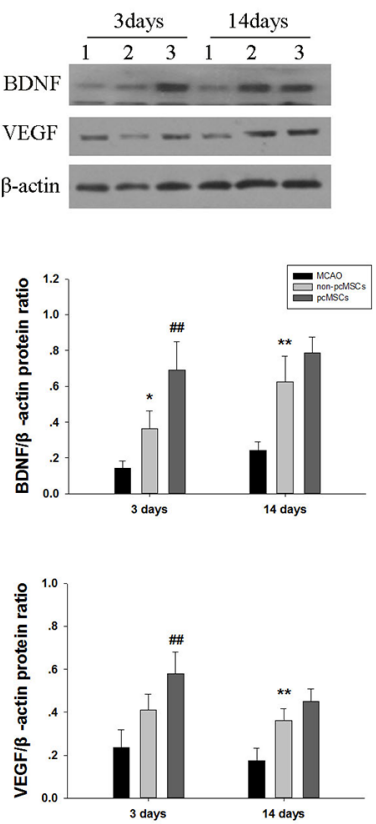
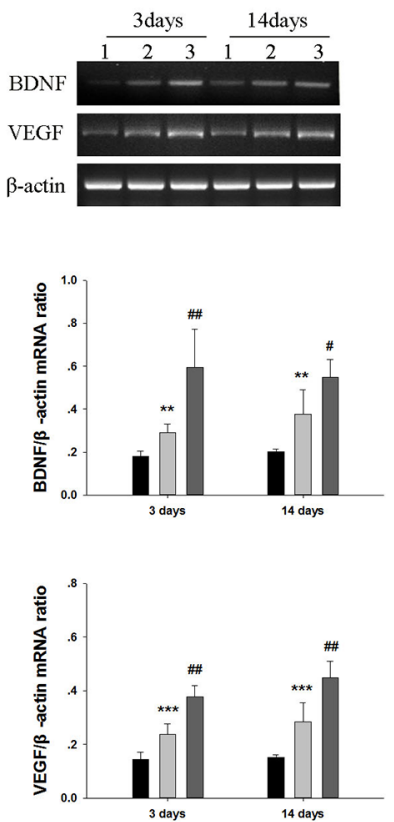

Figure 6: Administration of ${ }^{\mathrm{PC}} \mathrm{BMSCs}$ alleviated MACO-induced apoptosis, decreased Bax/Bcl-2 ratio and increased BDNF and VEGF expression. (A) Representative photomicrographs $(\times 20)$ of TUNEL staining of the brain tissues. Bar graphs showing quantification of TUNEL-positive cells. Scale bar $=50 \mu \mathrm{m} . n=4$. (B) The protein and mRNA levels of Bax and Bcl-2 in injured cerebral tissues at day 3 and 14 after BMSCs transplantation were then analyzed by Western blot and semiquantitative RT-PCR, $\beta$-actin served as a loading control. Results were expressed as Bax/Bcl-2 ratio. $n=4$. (C) The protein and mRNA levels of BDNF and VEGF in injured cerebral tissues at day 3 and 14 after BMSCs transplantation were then analyzed by Western blot and semiquantitative RT-PCR, $\beta$-actin served as a loading control. Each value was normalized to $\beta$-actin. $n=4$.Values represent the mean $\pm \mathrm{SD}^{*} p<0.05, * * p<0.01, * * * p<0.001$ non-PC BMSCs VS MACO; $\# p<0.05, \# \# p 0.01{ }^{\mathrm{PC}} \mathrm{BMSCs}$ VS non-PCBMSCs. 
the bioactive factors released from $\mathrm{H}_{2} \mathrm{~S}$-preconditioned BMSCs provided protective effects on neurons subjected to injury, we treated MCAO animals with NaHS $(1 \mu \mathrm{M})$ via tail vein in preliminary studies, the results showed that NaHS administration alone did not protect neurons from hypoxia-ischemia injury in vivo. Taking together these data and the results of the present study, we hypothesize that enhancement of paracrine effects of BMSCs for these neuroprotective factors may be indirectly resulted from improvement of the transplanted BMSCs survival due to preconditioning with $\mathrm{H}_{2} \mathrm{~S}$.

Angiogenesis can improve the micro-circulation in the zone of cerebral ischemia and inhibit the cell apoptosis. Moreover, the new blood vessels can induce the release of nutritional factors to promote the recovery of neurological function. In this study, we found that $\mathrm{H}_{2} \mathrm{~S}$ preconditioned BMSCs can promote the angiogenesis after cerebral infarction by CD31 staining, associated with enhanced secretion of VEGF. These results are similar to those in the previous studies $[34,35]$. Thus it can be presumed that the reason for $\mathrm{H}_{2} \mathrm{~S}$-preconditioned BMSCs to recover the neurological function of animals with cerebral infarction may be the action to promote the angiogenesis. In addition, we found that hypoxia do not increase the VEGF expression in BMSCs, which is in contradiction with a numerous number of previous data $[36,37]$. The discrepancy might be due to the severity of the insult and the time used in these studies.

In the cerebral ischemia, HIF-1 $\alpha$ was increased and it induced the expression level of its downstream target genes, such as VEGF, erythropoietin, and CXC chemokine receptor 4 [38]. HIF-1 $\alpha$ is also involved in angiogenesis, cell survival, anaerobic metabolism, cell migration, and differentiation, suggesting that HIF-1 $\alpha$ plays an important role in the functional recovery of cerebral ischemia [38]. Previous studies showed that $\mathrm{H}_{2} \mathrm{~S}$ increased HIF-1 $\alpha$ and VEGF expression in vascular smooth muscle cells under hypoxic condition, which enhanced endothelial cell viability $[39,40]$. Recently, one study showed that HIF-1 $\alpha$ induced VEGF overexpression in BMSCs protected neuron against brain ischemia [36]. Our findings are in agreement with these previous reports and revealed that BMSCs preconditioned by NaHS could enhance secretion of HIF$1 \alpha$ and VEGF, associated with a decreased apoptotic rate, suggesting that the NaHS-preconditioned BMSCs promote cellular survival through the regulation of VEGF by HIF-1 $\alpha$.

In this regard, it is important to note that a recent study indicated that therapeutic efficacy of rat BMSCs preconditioned with $200 \mu \mathrm{M}$ NaHS added after myocardial ischemia in Sprague-Dawley rats [41], thus the used cells received much higher dose of $\mathrm{H}_{2} \mathrm{~S}$ compared to the cells applied in our study. In our study NaHS at lower concentration can improve the survival of stem cells used for cell-therapy in the context of an in vitro cell therapy. Similar results were reported by other authors, who demonstrated that NaHS at $3 \mu \mathrm{M}$ pretreatment can increase the survival of therapeutically used human adipose tissue-derived stem cells [42]. There are several important differences between these investigations. For example, in this study BMSCs were challenged to hypoxia for $72 \mathrm{~h}$ in $1 \%$ FBS medium, for the BMSCs failed to proliferate in serum-free conditions [43].

There are some important limitations to our study. First, whether $\mathrm{H}_{2} \mathrm{~S}$ preconditioning change property of BMCSs which differentiate into neuronal lineage cells was not investigated. Second, how $\mathrm{H}_{2} \mathrm{~S}$ up-regulates expression of BDNF and VEGF, and how these cytokines affect the neurological function were not determined. Finally, how the effects of $\mathrm{H}_{2} \mathrm{~S}$ preconditioning using other routes/ timing of stem cell delivery were not evaluated.

In conclusion, we have demonstrated that $\mathrm{H}_{2} \mathrm{~S}$ preconditioning presented better neuron protection and an improvement of neurological function under hypoxicischemic conditions, which might provide a better therapy of BMSCs administration to cerebral ischemia. We have also elucidated the possible mechanisms of the beneficial effects of $\mathrm{H}_{2} \mathrm{~S}$ preconditioned BMSCs acting, at least in part, through up-regulation of the survival of BMSCs and secretion of paracrine factors.

\section{MATERIALS AND METHODS}

\section{Bone marrow mesenchymal stem cell cultures}

Bone marrow mesenchymal stem cells (BMSCs) were harvested from 3 weeks Wistar rats as previously described [44]. Briefly, BMSCs were flushed out from the femoral and tibial bones of donor adult rats using a syringe and 20-gauge needle. The cells were suspended in DMEM/ F12 supplemented with 10\% FBS and incubated in $95 \%$ room air and $5 \%$ carbon dioxide at $37^{\circ} \mathrm{C}$ and nonadherent cells were removed by replacing the medium. The primary cultures were passaged at a ratio of 1:3 once the BMSCs reached $80-90 \%$ confluence. At passage 3, BMSCs were used for the present study.

\section{Hypoxia-ischemic protocol}

Prior to use in the experiment, plated cells were incubated with low serum (1\% FBS) for $1 \mathrm{~h}$. The medium was then replaced with low serum DMEM containing NaHS (Sigma-Aldrich) for the various time intervals and concentrations as indicated below. PI3K inhibitors (Wortmannin ) and ERK1/2-MAPK inhibitor (PD98059) were purchased from Sigma-Aldrich.

BMSCs were challenged to hypoxia by placing them in a chamber (Model: Heraeus HERAcell 240i; Thermo Scientific, USA) filled with $3 \%$ oxygen, $5 \% \mathrm{CO}_{2}$ and $92 \%$ nitrogen at $37^{\circ} \mathrm{C}$ for the time intervals indicated below. BMSCs serving as controls were incubated at $37^{\circ} \mathrm{C}$ with 95\% air and $5 \% \mathrm{CO}_{2}$. Three or more different donor BMSCs were evaluated in triplicate for all experiments. 


\section{Cell viability assay}

Cell viability was determined by the MTT assay. BMSCs were plated into 96-well culture plates at a density of $5 \times 10^{4}$ cells $/ \mathrm{ml}$ with $200 \mu \mathrm{l}$ culture medium per well. Following exposure to hypoxia with or without differing concentrations of NaHS, $20 \mu \mathrm{l}$ MTT solution $(5 \mathrm{mg} / \mathrm{ml})$ was added to each well and incubated for $4 \mathrm{~h}$. The medium was then aspirated and $200 \mu$ dimethyl sulfoxide was added. The absorbance value was measured using a multiwell spectrophotometer (Bio-Rad, USA) at $490 \mathrm{~nm}$. Cell viability was expressed as a percentage of viable cells obtained relative to that of controls.

\section{Crystal violet assay}

BMSCs were treated with test substances or vehicle for $72 \mathrm{~h}$, and then fixed with $4 \%$ paraformaldehyde, stained with $0.5 \%$ crystal violet in $4 \%$ paraformaldehyde. The number of colonies was then counted. Colonies of less than $2 \mathrm{~mm}$ in diameter and faintly stained colonies were ignored [45].

\section{Proliferation index by bromodeoxyuridine (BrdU) labeling}

Cell proliferation was evaluated by BrdU incorporation assay. Dissociated BMSCs were transferred into 12-well plates with poly-D-lysine coated coverslips in medium. After this, BMSCs were treated with test substances or vehicle for $72 \mathrm{~h}$ and incubated with BrdU (10 $\mu \mathrm{mol} / \mathrm{l}$, Sigma-Aldrich) for $2 \mathrm{~h}$. The cultured cells were fixed in $4 \%$ paraformaldehyde for $20 \mathrm{~min}$, treated with $2 \mathrm{~mol} / 1 \mathrm{HCl}$ at $37^{\circ} \mathrm{C}$ for $30 \mathrm{~min}$, blocked with $10 \%$ normal goat serum for $30 \mathrm{~min}$, and incubated with antiBrdU monoclonal antibody (1:250; Sigma-Aldrich) overnight at $4^{\circ} \mathrm{C}$. Goat anti-mouse IgG coupled to tetramethyl rhodamine iso-thiocyanate (TRITC) $(1: 200$; Chemicon, Temecula, CA, USA) was used as the secondary antibody. The percentage of BrdU-positive cells over total DAPI cells was determined by randomly counting 10-nonoverlapping microscopy fields from each condition, in at least four independent experiments. Counting was performed in a blinded manner.

\section{Apoptosis analysis in vitro}

The TUNEL assay for the detection of morphological features of apoptotic cell death was performed by using the in situ cell detection kit (FITC) following the manufacturer's instructions (Chemicon, Temecula, CA, USA). The features of apoptosis were examined, as described previously [46]. Images of TUNEL-positive cells (with a green fluorescent nucleus) were captured with a fluorescence microscope (IX71; Olympus, Tokyo, Japan) and randomly counted in 10-nonoverlapping microscopy fields from each experimental condition, in at least four independent experiments. The proportion of TUNEL-positive cells was expressed as the percentage of the total cells counted. Counting was performed in a blinded manner.

\section{Detection of mitochondrial membrane potential (MMP or $\Delta \Psi \mathrm{m}$ )}

The loss of $\Delta \Psi \mathrm{m}$ was determined using the JC-1 Mitochondrial Membrane Potential assay kit following the manufacturer's instructions (Beyotime Institute of Biotechnology, China). Briefly, BMSCs were treated with test substances or vehicle for $72 \mathrm{~h}$. Following treatment, BMSCs were washed with PBS and added JC-1 $(5 \mu \mathrm{M})$, followed by incubation at $37^{\circ} \mathrm{C}$ for $20 \mathrm{~min}$. Subsequently, BMSCs were washed twice with cold JC-1 staining buffer and visualized under a fluorescence microscope. The ratio of red to green fluorescence intensity was measured and data were expressed as relative to the mean sham value.

\section{Ischemia model of middle cerebral artery occlusion}

Adult male Wistar rats (270 to $300 \mathrm{~g}$ ) were used for ischemic stroke experiments. A middle cerebral artery occlusion (MCAO) was induced by a modification of the intraluminal vascular occlusion method as previously described [47]. Briefly, Rats were initially anesthetized with $10 \%$ chloral hydrate. Rectal temperature was controlled at $37^{\circ} \mathrm{C}$ with a feedback-regulated water heating system. The right common carotid artery, external carotid artery (ECA), and internal carotid artery were exposed. A 3.0 monofilament nylon suture $(18.5 \mathrm{~mm}$, determined by animal weight), with its tip rounded by heating near a flame, was advanced from the ECA into the lumen of the internal carotid artery until it blocked the origin of the middle cerebral artery. At $2 \mathrm{~h}$ after occlusion, the animals were re-anesthetized and reperfused by withdrawing the suture until its tip cleared the lumen of the ECA.

\section{Intravenous administration of BMSCs}

NaHS was added to the cell culture medium (final concentration: $1 \mu \mathrm{M}$ ) for $72 \mathrm{~h}$, followed by drug washout before transplantations. Then the deposits of single cell suspension in PBS $\left(2 \times 10^{6}\right.$ cells per $\left.\mathrm{ml}\right)$ was pre-incubated with or without NaHS (final concentration: $1 \mu \mathrm{M}$ ) for 30 min before transplantation.

After $2 \mathrm{~h} \mathrm{MCAO}$ and $24 \mathrm{~h}$ reperfusion, rats were randomly divided into three groups: MACO group (rats given MCAO without cell administration but with $1 \mathrm{ml} \mathrm{PBS}$ ), ${ }^{\text {non-PC}}$ BMSCs group (rats transplanted with $2 \times 10^{6} \mathrm{BMSCs}$ ), and ${ }^{\mathrm{PC}} \mathrm{BMSCs}$ group (rats transplanted with $2 \times 10^{6} \mathrm{NaHS}$ preconditioning-BMSCs) via tail vein. For intravenous injection, BMSCs $\left(2 \times 10^{6}\right)$ diluted in $1 \mathrm{ml}$ PBS were injected slowly for five minutes in the tail vein. All transplantation procedures were performed under aseptic conditions. 


\section{Behavioral tests}

All animals were assessed with modified neurological severity score (mNSS) tests [48] (Table 1) at day 1,3 and 14 after BMSCs transplantation $(n=6$ for each group). Neurological function including motor and sensory systems as well as reflexes and a balance test is graded on a numeric scale from 0 to 18 (normal score, 0 ; maximal deficit score, 18); the higher the score, the more severe the neurological deficit.

\section{Cerebral infarction measurement}

Cerebral infarction volume was measured by staining brain slices with triphenyltetrazolium chloride (TTC; Sigma) at day 14 after BMSCs transplantation. The animals ( $n=3$ for each group) were decapitated under deep anesthesia with $10 \%$ chloral hydrate $(0.8 \mathrm{~g} / \mathrm{kg}$, i.p.). The brains were quickly removed and sliced into 6 coronal sections. The slices were incubated in a $2 \%$ solution of TTC at $37^{\circ} \mathrm{C}$ for $30 \mathrm{~min}$ and then fixed in a $10 \%$ formaldehyde solution overnight. The infarct area of each brain slice was analyzed using the Image-Pro plus 6.0 analysis software. The total infarction volume for each brain was calculated by summation of the infarcted area of all brain slices.

\section{Hematoxylin and eosin staining}

At day 14 after BMSCs transplantation, animals were perfused under deep anesthesia with $10 \%$ chloral hydrate followed by $4 \%$ paraformaldehyde. The brains were then removed and post-fixed in formalin. After fixation and dehydration with gradient ethanol, the brain tissues were embedded in paraffin and sliced into in the coronal plane at $4 \mu \mathrm{m}$ thickness using a section cutter (Leica, Germany). The sections (3 sections/rat) were stained with hematoxylin and eosin (H\&E). And 4 rats for each group were prepared for HE staining. Morphology of ipsilateral cortex was observed by a light microscope (Olympus Corporation, Japan).

\section{Immunohistochemistry}

The sections were dewaxed with a standard procedure and washed with PBS as described previously. Briefly, after blocking in $10 \%$ normal goat serum in PBS for $30 \mathrm{~min}$ at room temperature, the sections were incubated with anti-microtubule- associated protein 2 (MAP-2) (1:200; mouse monoclonal, Millipore Corporation, Billerica, MA, USA), CD 31(1:200; rabbit polyclonal, Cell Signaling Tech. MA, USA) at $4^{\circ} \mathrm{C}$ overnight. After primary antibody incubation, samples were washed and incubated with a goat anti-mouse/rabbit secondary antibody for $2 \mathrm{~h}$ at room temperature. The sections were washed and then incubated with an avidin biotinylated enzyme complex for $1 \mathrm{~h}$ at room temperature.
The sections were visualized with diaminobenzidine. Nuclei were counterstained with hematoxylin. Finally, the sections were dehydrated in an alcohol gradient and cleared with xylene. The number of CD31-positive cells was counted in penumbra of hemisphere with the lesion under the light microscope $(20 \times)$. For each section, five visual fields in penumbra of hemisphere with the lesion were chosen at random for statistical analysis ( $n=4$ each group). Results were expressed as the mean number of CD31 positive cells per $\mathrm{mm}^{2}$.

\section{TUNEL staining in vivo}

The sections were dewaxed with a standard procedure and washed with PBS as described previously. TUNEL staining was done with commercially available kit as above described. The slides were counterstained with DAPI for total nuclei counting. The number of total and TUNEL-positive cells in the ischemic penumbra was calculated by counting six randomly selected microscopic fields in sections obtained from each rat $(n=4)$ at $\times 20$ objective by a blinded observer. The percentage of TUNEL-positive cells against the total number of cells was calculated and averaged.

\section{Reverse transcription-polymerase chain reaction (RT-PCR)}

Total RNA was extracted from cells using the Trizol reagent (Gibco, Invitrogen) according to the manufacturer's instructions. RNA concentration was determined using a spectrophotometer (Bio-Rad. Labs) at $260 \mathrm{~nm}$. Identical amounts of RNA $(2 \mu \mathrm{g})$ were reversely transcribed into cDNA using a commercial RTPCR kit (Fermentas, Vilnius, Lithuania) according to the manufacturer's instructions. cDNA was subsequently amplified by PCR with specific primers (Table 2). PCR products, separated on a $1.2 \%$ agarose/TAE gel, were visualized by staining with ethidium bromide. The densitometric calculations of these values were normalized to $\beta$-actin. The intensity of bands was determined using Image-Pro Plus 6.0 software.

\section{Western blot analysis}

Protein concentration in the supernatants of cells or ipsilateral cortex was determined using a BCA protein assay kit (Pierce Biotechnology, Inc.). A quantity of $30-50 \mu \mathrm{g}$ of total proteins was loaded onto a $10-15 \%$ gradient polyacrylamide gel, electrophoretically transferred to a polyvinylidene difluoride membrane and probed with the following primary antibodies: Bax antibody (1:1000, Santa Cruz Biotechnology, CA, USA), Bcl-2 antibody (1:1000, Santa Cruz Biotechnology), Cleaved caspase-3 (1:500, Cell Signaling Tech. MA, USA), Caspase-3 (1:1000, Cell Signaling), Phosphoextracellular signal-regulated kinase (ERK) $1 / 2$ 
Motor tests

Raising rat by the tail

1 Flexion of forelimb

1 Flexion of hindlimb

1 Head moved $>10^{\circ}$ to vertical axis within $30 \mathrm{~s}$

Placing rat on the floor $($ normal $=0 ;$ maximum $=3$ )

0 Normal walk

1 Inability to walk straight

2 Circling toward the paretic side

3 Fall down to the paretic side

Sensory tests

1 Placing test (visual and tactile test)

2 Proprioceptive test (deep sensation, pushing the paw against the table edge to stimulate limb muscles)

Beam balance tests $($ normal $=0 ;$ maximum $=6$ )

0 Balances with steady posture

1 Grasps side of beam

2 Hugs the beam and one limb falls down from the beam

3 Hugs the beam and two limbs fall down from the beam, or spins on beam ( $>60 \mathrm{~s})$

4 Attempts to balance on the beam but falls off ( $>40 \mathrm{~s})$

5 Attempts to balance on the beam but falls off ( $>20 \mathrm{~s})$

6 Falls off: No attempt to balance or hang on to the beam $(<20 \mathrm{~s})$

Reflexes absent and abnormal movements

1 Pinna reflex (head shake when touching the auditory meatus)

1 Corneal reflex (eye blink when lightly touching the cornea with cotton)

1 Startle reflex (motor response to a brief noise from snapping a clipboard paper)

1 Seizures, myoclonus, myodystony

Maximum points

One point is awarded for the inability to perform the tasks or for the lack of a tested reflex; 13 to 18 indicates severe injury;

7 to 12 , moderate injury; 1 to 6 , mild injury.

Table 2: PCR primers used in this study

\begin{tabular}{lll}
\hline \multicolumn{1}{c}{ Gene } & \multicolumn{1}{c}{ Forword $\left(\mathbf{5}^{\prime} \rightarrow \mathbf{3}^{\prime}\right)$} & \multicolumn{1}{c}{ Reverse $\left(\mathbf{5}^{\prime} \rightarrow \mathbf{3}^{\prime}\right)$} \\
\hline Bax & GGT TGC CCT CTT CTA CTT TGC & TCT TCC AGA TGG TGA GCG AG \\
Bcl-2 & GGA TGA CTT CTC TCG TCG CTA C & TGA CAT CTC CCT GTT GAC GCT \\
BDNF & AGC TGA GCG TGT GTG ACA GT & ACC CAT GGG ATT ACA CTT GG \\
VEGF & GTG GAC ATC TTC CAG GAG TA & TCT GCA TTC ACA TCT GCT GT \\
$\beta$-actin & CTA TTG GCA ACG AGC GGT TCC & CAG CAC TGT GTT GGC ATA GAG G \\
\hline
\end{tabular}


(1:2000, Cell Signaling), ERK1/2 (1:2000; Cell Signaling), Phospho-Akt (Ser 473) (1:500, Cell Signaling), Akt (1:1000; Cell Signaling), Brain-derived neurotrophic factor (BDNF, 1:1000, Santa Cruz Biotechnology), Vascular endothelial growth factor (VEGF, 1:100, Santa Cruz Biotechnology). $\beta$-actin (1:2000; Sigma-Aldrich) was used as an internal control. Secondary antibodies were horseradish peroxidase conjugated to goat/mouse anti-rabbit IgG (1:8000, Sigma-Aldrich). The membranes were developed using an enhanced chemiluminescence detection system (Pierce, Rockford, IL).

\section{Statistical analysis}

Quantitative data were presented as the mean \pm SD. Statistical analysis of data was performed with a oneway ANOVA using the post-hoc Tukey test for multiple comparisons of means. Differences were considered statistically significant if the $p$ value was $<0.05$.

\section{Abbreviations}

BDNF, brain-derived neurotrophic factor; BMSCs, Bone marrow mesenchymal stem cells ; CNS, Central nervous system; DAPI, 4', 6-Diamidino-2-phenylindole dihydrochloride; DMEM, Dulbecco's modified Eagle medium; ELISA, Enzyme-Linked Immunosorbent Assay; ERK, extracellular signal-regulated kinase; FBS, fetal bovine serum ; $\mathrm{H}_{2} \mathrm{~S}$, hydrogen sulfide; MTT, 3-[4, 5-dimethylthiazol-2-yl] -2, 5-diphenyltetrazolium bromide sodium; MAPK, mitogen-activated protein kinase; NaHS, sodium hydrosulfide; PBS, phosphate buffered saline; RT-PCR, reverse transcription-polymerase chain reaction; VEGF, vascular endothelial growth factor.

\section{ACKNOWLEDGMENTS AND FUNDING}

This work was supported by funding from the Fundamental Research Funds of Shandong University (No.2015JC008); National Natural Science Foundation of China (No.81200879, 31300952); The Foundation for Outstanding Young Scientist in Shandong Province (No.2013BSE27020).

\section{CONFLICTS OF INTEREST}

The authors have no conflict of interest to declare.

\section{Authors' contributions}

ZW was involved in study design, data interpretation and writing of the manuscript; DXL was involved in study design, data interpretation and manuscript editing; QZ performed the majority of the laboratory work and contributed to the analysis of data; SL, TL, HSL and XEW were responsible for the animal model; LY and FWW were responsible for cell culture; SLW was responsible for western blot. AJH was involved in manuscript editing. The authors have no conflict of interest to declare.

\section{REFERENCES}

1. Bliss T, Guzman R, Daadi M, Steinberg GK. Cell transplantation therapy for stroke. Stroke. 2007; 38:817-826.

2. Meamar R, Dehghani L, Ghasemi M, Khorvash F, Shaygannejad V. Stem cell therapy in stroke: a review literature. International journal of preventive medicine. 2013; 4:S139-146.

3. Doeppner TR, Hermann DM. Mesenchymal stem cells in the treatment of ischemic stroke: progress and possibilities. Stem Cells Cloning. 2010; 3:157-163.

4. Zhao S, Wehner R, Bornhauser $\mathrm{M}$, Wassmuth $\mathrm{R}$, Bachmann M, Schmitz M. Immunomodulatory properties of mesenchymal stromal cells and their therapeutic consequences for immune-mediated disorders. Stem cells and development. 2010; 19:607-614.

5. Chopp M, Li Y, Zhang ZG. Mechanisms underlying improved recovery of neurological function after stroke in the rodent after treatment with neurorestorative cell-based therapies. Stroke. 2009; 40:S143-145.

6. Chen J, Zhang ZG, Li Y, Wang L, Xu YX, Gautam SC, Lu M, Zhu Z, Chopp M. Intravenous administration of human bone marrow stromal cells induces angiogenesis in the ischemic boundary zone after stroke in rats. Circulation research. 2003; 92:692-699.

7. Wang R. Physiological implications of hydrogen sulfide: a whiff exploration that blossomed. Physiological reviews. 2012; 92:791-896.

8. Kimura Y, Kimura H. Hydrogen sulfide protects neurons from oxidative stress. Faseb J. 2004; 18:1165-1167.

9. Kimura H. Physiological role of hydrogen sulfide and polysulfide in the central nervous system. Neurochemistry international. 2013; 63:492-497.

10. Hu LF, Wong PT, Moore PK, Bian JS. Hydrogen sulfide attenuates lipopolysaccharide-induced inflammation by inhibition of p38 mitogen-activated protein kinase in microglia. Journal of neurochemistry. 2007; 100:1121-1128.

11. Wang JF, Li Y, Song JN, Pang HG. Role of hydrogen sulfide in secondary neuronal injury. Neurochemistry international. $2014 ; 64: 37-47$.

12. Zhang Q, Yuan L, Liu D, Wang J, Wang S, Zhang Q, Gong Y, Liu H, Hao A, Wang Z. Hydrogen sulfide attenuates hypoxia-induced neurotoxicity through inhibiting microglial activation. Pharmacol Res. 2014; 84:32-44.

13. Wang Z, Zhan J, Wang X, Gu J, Xie K, Zhang Q, Liu D. Sodium hydrosulfide prevents hypoxia-induced behavioral impairment in neonatal mice. Brain research. 2013; 1538:126-134.

14. Liu D, Wang Z, Zhan J, Zhang Q, Wang J, Zhang Q, Xian X, Luan Q, Hao A. Hydrogen sulfide promotes 
proliferation and neuronal differentiation of neural stem cells and protects hypoxia-induced decrease in hippocampal neurogenesis. Pharmacology, biochemistry, and behavior. 2014; 116:55-63.

15. Guo Z, Li CS, Wang CM, Xie YJ, Wang AL. CSE/H2S system protects mesenchymal stem cells from hypoxia and serum deprivation induced apoptosis via mitochondrial injury, endoplasmic reticulum stress and PI3K/Akt activation pathways. Molecular medicine reports. 2015; 12:2128-2134.

16. Gottlieb E, Armour SM, Harris MH, Thompson CB. Mitochondrial membrane potential regulates matrix configuration and cytochrome $\mathrm{c}$ release during apoptosis. Cell death and differentiation. 2003; 10:709-717.

17. Hu LF, Lu M, Wu ZY, Wong PT, Bian JS. Hydrogen sulfide inhibits rotenone-induced apoptosis via preservation of mitochondrial function. Mol Pharmacol. 2009; 75:27-34.

18. Luo Y, Yang X, Zhao S, Wei C, Yin Y, Liu T, Jiang S, Xie J, Wan X, Mao M, Wu J. Hydrogen sulfide prevents OGD/Rinduced apoptosis via improving mitochondrial dysfunction and suppressing an ROS-mediated caspase-3 pathway in cortical neurons. Neurochemistry international. 2013; 63:826-831.

19. Li Z, Wang Y, Xie Y, Yang Z, Zhang T. Protective effects of exogenous hydrogen sulfide on neurons of hippocampus in a rat model of brain ischemia. Neurochem Res. 2011; 36:1840-1849.

20. Wang Z, Zhan J, Wang X, Gu J, Xie K, Zhang Q, Liu D. Sodium hydrosulfide prevents hypoxia-induced behavioral impairment in neonatal mice. Brain Res. 2013.

21. Lu M, Hu LF, Hu G, Bian JS. Hydrogen sulfide protects astrocytes against $\mathrm{H}(2) \mathrm{O}(2)$-induced neural injury via enhancing glutamate uptake. Free Radic Biol Med. 2008; 45:1705-1713.

22. Rauch J, Volinsky N, Romano D, Kolch W. The secret life of kinases: functions beyond catalysis. Cell Commun Signal. 2011; 9:23.

23. White BC, Sullivan JM, DeGracia DJ, O'Neil BJ, Neumar RW, Grossman LI, Rafols JA, Krause GS. Brain ischemia and reperfusion: molecular mechanisms of neuronal injury. Journal of the neurological sciences. 2000; 179:1-33.

24. Peake BF, Nicholson CK, Lambert JP, Hood RL, Amin H, Amin S, Calvert JW. Hydrogen sulfide preconditions the $\mathrm{db} / \mathrm{db}$ diabetic mouse heart against ischemiareperfusion injury by activating Nrf2 signaling in an Erkdependent manner. American journal of physiology. 2013; 304:H1215-1224.

25. Zhang Q, Fu H, Zhang H, Xu F, Zou Z, Liu M, Wang Q, Miao M, Shi X. Hydrogen sulfide preconditioning protects rat liver against ischemia/reperfusion injury by activating Akt-GSK-3beta signaling and inhibiting mitochondrial permeability transition. PloS one. 2013; 8:e74422.

26. Perasso L, Cogo CE, Giunti D, Gandolfo C, Ruggeri P, Uccelli A, Balestrino M. Systemic administration of mesenchymal stem cells increases neuron survival after global cerebral ischemia in vivo (2VO). Neural plasticity. 2010; 2010:534925.

27. Dharmasaroja P. Bone marrow-derived mesenchymal stem cells for the treatment of ischemic stroke. J Clin Neurosci. 2009 ; 16:12-20.

28. Zhang ZG, Zhang L, Jiang Q, Zhang R, Davies K, Powers C, Bruggen N, Chopp M. VEGF enhances angiogenesis and promotes blood-brain barrier leakage in the ischemic brain. The Journal of clinical investigation. 2000; 106:829-838.

29. Schabitz WR, Sommer C, Zoder W, Kiessling M, Schwaninger M, Schwab S. Intravenous brain-derived neurotrophic factor reduces infarct size and counterregulates Bax and Bcl-2 expression after temporary focal cerebral ischemia. Stroke. 2000; 31:2212-2217.

30. Ding J, Cheng Y, Gao S, Chen J. Effects of nerve growth factor and Noggin-modified bone marrow stromal cells on stroke in rats. Journal of neuroscience research. 2011; 89:222-230.

31. Jang H, Oh MY, Kim YJ, Choi IY, Yang HS, Ryu WS, Lee SH, Yoon BW. Hydrogen sulfide treatment induces angiogenesis after cerebral ischemia. Journal of neuroscience research. 2014; 92:1520-1528.

32. Jiang JM, Zhou CF, Gao SL, Tian Y, Wang CY, Wang L, Gu HF, Tang XQ. BDNF-TrkB pathway mediates neuroprotection of hydrogen sulfide against formaldehydeinduced toxicity to PC12 cells. PloS one. 2014; 10:e119478.

33. Wei HJ, Xu JH, Li MH, Tang JP, Zou W, Zhang $\mathrm{P}$, Wang L, Wang CY, Tang XQ. Hydrogen sulfide inhibits homocysteine-induced endoplasmic reticulum stress and neuronal apoptosis in rat hippocampus via upregulation of the BDNF-TrkB pathway. Acta pharmacologica Sinica. 2014; 35:707-715.

34. Streeter E, Ng HH, Hart JL. Hydrogen sulfide as a vasculoprotective factor. Med Gas Res. 2013; 3:9.

35. Holwerda KM, Burke SD, Faas MM, Zsengeller Z, Stillman IE, Kang PM, van Goor H, McCurley A, Jaffe IZ, Karumanchi SA, Lely AT. Hydrogen Sulfide Attenuates sFlt1-Induced Hypertension and Renal Damage by Upregulating Vascular Endothelial Growth Factor. J Am Soc Nephrol. 2013.

36. Zhong Q, Zhou Y, Ye W, Cai T, Zhang X, Deng DY. Hypoxia-inducible factor 1-alpha-AA-modified bone marrow stem cells protect PC12 cells from hypoxia-induced apoptosis, partially through VEGF/PI3K/Akt/FoxO1 pathway. Stem cells and development. 2012; 21:2703-2717.

37. Wei L, Fraser JL, Lu ZY, Hu X, Yu SP. Transplantation of hypoxia preconditioned bone marrow mesenchymal stem cells enhances angiogenesis and neurogenesis after cerebral ischemia in rats. Neurobiology of disease. 2012; 46:635-645.

38. Sharp FR, Bernaudin M. HIF1 and oxygen sensing in the brain. Nature reviews Neuroscience. 2004; 5:437-448. 
39. Liu X, Pan L, Zhuo Y, Gong Q, Rose P, Zhu Y. Hypoxiainducible factor-1alpha is involved in the pro-angiogenic effect of hydrogen sulfide under hypoxic stress. Biological \& pharmaceutical bulletin. 2010; 33:1550-1554.

40. Bir SC, Kolluru GK, McCarthy P, Shen X, Pardue S, Pattillo CB, Kevil CG. Hydrogen sulfide stimulates ischemic vascular remodeling through nitric oxide synthase and nitrite reduction activity regulating hypoxia-inducible factor-1alpha and vascular endothelial growth factordependent angiogenesis. Journal of the American Heart Association. 2012; 1:e004093.

41. Xie X, Sun A, Zhu W, Huang Z, Hu X, Jia J, Zou Y, Ge J. Transplantation of mesenchymal stem cells preconditioned with hydrogen sulfide enhances repair of myocardial infarction in rats. The Tohoku journal of experimental medicine. 2012; 226:29-36.

42. Dongo E, Benko Z, Csizmazia A, Marosi G, Grottke A, Jucker M, Schumacher U, Kiss L. H2S preconditioning of human adipose tissue-derived stem cells increases their efficacy in an in vitro model of cell therapy for simulated ischemia. Life sciences. 2014; 113:14-21.

43. Kim S, Chaudhry A, Lee I, Frank JA. Effects of long-term hypoxia and pro-survival cocktail in bone marrow-derived stromal cell survival. Stem cells and development. 2014; 23:530-540.
44. Wang FW, Jia DY, Du ZH, Fu J, Zhao SD, Liu SM, Zhang YM, Ling EA, Hao AJ. Roles of activated astrocytes in bone marrow stromal cell proliferation and differentiation. Neuroscience. 2009; 160:319-329.

45. Yoshimura H, Muneta T, Nimura A, Yokoyama A, Koga H, Sekiya I. Comparison of rat mesenchymal stem cells derived from bone marrow, synovium, periosteum, adipose tissue, and muscle. Cell and tissue research. 2007; 327:449-462.

46. Wang Z, Liu D, Wang J, Liu S, Gao M, Ling EA, Hao A. Cytoprotective effects of melatonin on astroglial cells subjected to palmitic acid treatment in vitro. J Pineal Res. 2012; 52:253-264.

47. Belayev L, Alonso OF, Busto R, Zhao W, Ginsberg MD. Middle cerebral artery occlusion in the rat by intraluminal suture. Neurological and pathological evaluation of an improved model. Stroke. 1996; 27:1616-1622; discussion 1623.

48. Chen J, Li Y, Wang L, Zhang Z, Lu D, Lu M, Chopp M. Therapeutic benefit of intravenous administration of bone marrow stromal cells after cerebral ischemia in rats. Stroke. 2001; 32:1005-1011. 